Old Dominion University

ODU Digital Commons

Psychology Theses \& Dissertations

Psychology

Summer 2002

\title{
Creating Inclusive Organizations: Its Meaning and Measurement
}

Bryan Christopher Hayes

Old Dominion University

Follow this and additional works at: https://digitalcommons.odu.edu/psychology_etds

Part of the Industrial and Organizational Psychology Commons, and the Organizational Behavior and Theory Commons

\section{Recommended Citation}

Hayes, Bryan C.. "Creating Inclusive Organizations: Its Meaning and Measurement" (2002). Doctor of Philosophy (PhD), Dissertation, Psychology, Old Dominion University, DOI: 10.25777/y915-b438 https://digitalcommons.odu.edu/psychology_etds/148

This Dissertation is brought to you for free and open access by the Psychology at ODU Digital Commons. It has been accepted for inclusion in Psychology Theses \& Dissertations by an authorized administrator of ODU Digital Commons. For more information, please contact digitalcommons@odu.edu. 
CREATING INCLUSIVE ORGANIZATIONS:

ITS MEANING AND MEASUREMENT

by

Bryan Christopher Hayes

B.S. August 1985, University of Kansas

B.S. December 1993, Old Dominion University

M.S. August 1996, Old Dominion University

A Dissertation Submitted to the Faculty of Old Dominion University in Partial

Fulfillment of the Requirement for the Degree of

DOCTOR OF PHILOSOPHY

INDUSTRIALORGANIZATIONAL PSYCHOLOGY

OLD DOMINION UNIVERSITY

August 2002

Approved by:

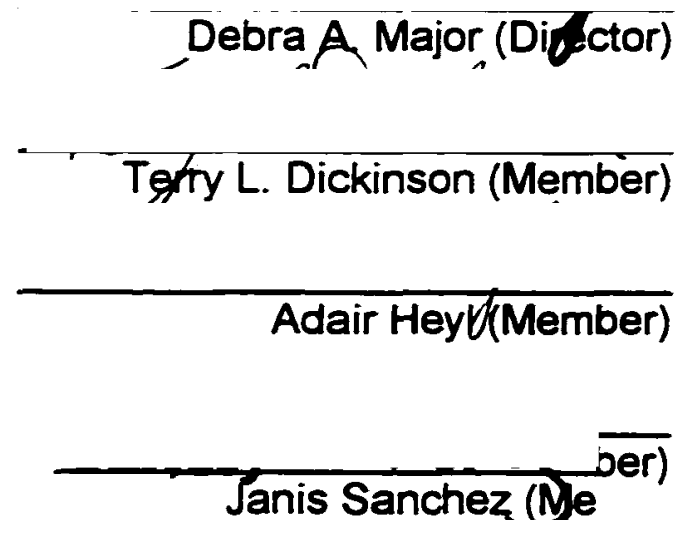




\author{
ABSTRACT \\ CREATING INCLUSIVE ORGANIZATIONS: \\ ITS MEANING AND MEASUREMENT \\ Bryan Christopher Hayes \\ Old Dominion University, 2002 \\ Director. Dr. Debra A. Major
}

There is growing interest in the concept of inclusion by both scientists and practitioners. The goal of the current study was to bring empirical support to the organizational inclusion literature. Inclusion was defined as a psychosocial need and a model was developed specifying its relationship to antecedent and consequence variables. The measurement model was explored with a sample of responses from 418 undergraduate students (Study 1 ). The measurement model was confirmed and the structural model was assessed with a sample of responses from 609 employees of a medical center (Study 2). Results of structural equation modeling provided limited support for the inclusion construct and poor support for the proposed measurement and structural models. While results supported the existence of an inclusive construct, there was little support for the efficacy of inclusion to understand attitudes in the context of organizations. Limitations of the present study and suggestions for future research are discussed. 
This dissertation is dedicated to Melissa and Lee.

Reproduced with permission of the copyright owner. Further reproduction prohibited without permission. 


\section{ACKNOWLEDGMENTS}

The completion of this dissertation would not have been possible without the assistance, encouragement, and support of many people. First, I would like to thank my dissertation chair, Debra Major, over the years she has been my advisor, confidant, friend, and much more. I would also like to thank each member of my dissertation committee. Terry Dickinson has had a tremendous influence on my professional development acting as a mentor and role model. Adair Heyl made the execution of this dissertation a win-win for myself and for her organization. Janis Sanchez provided insightful guidance and direction on the project. Next, I would like to thank my parents who have always supported the pursuit of my dreams. More recently, they helped me understand that my accomplishments were for myself, but also for those closest to me. Finally, I would like to thank my family. Melissa's insistent belief in my abilities and unyielding support kept me going through the toughest obstacles. Her own sacrifices provided me with the time needed to complete this project. Lee provided much needed smiles and hugs during long hours of work. 
TABLE OF CONTENTS

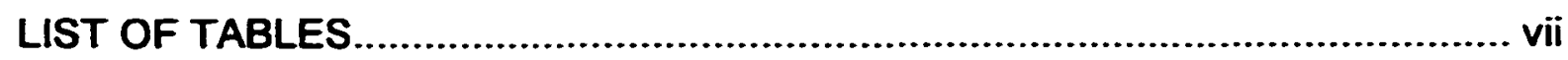

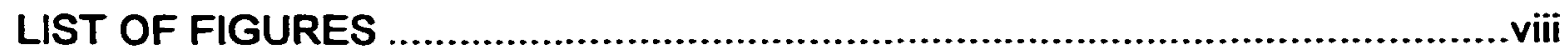

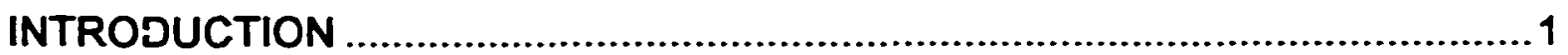

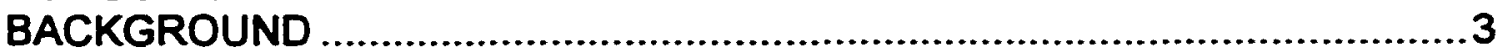

DEFINING INCLUSION IN ORGANIZATIONS .........................................

THE ROLE OF INCLUSION IN ORGANIZATIONS ................................13

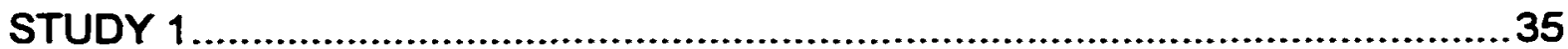

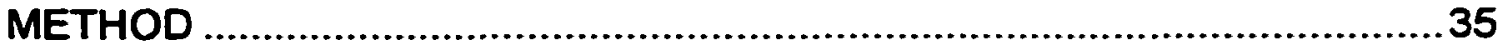

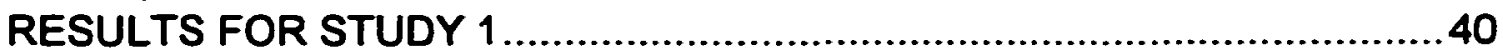

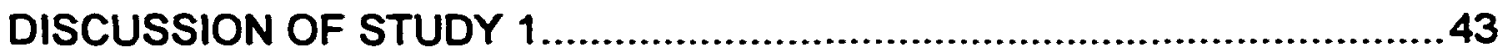

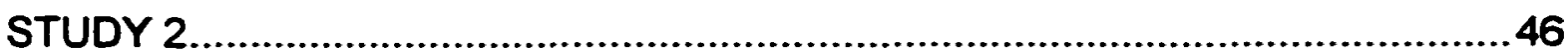

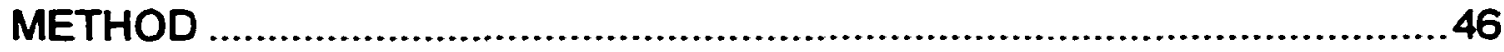

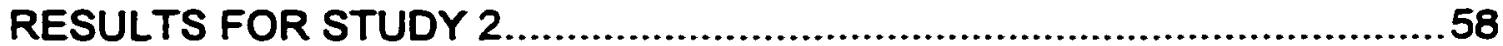

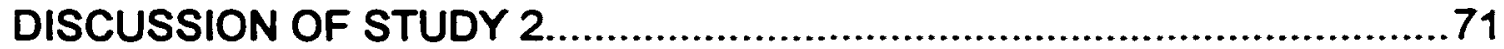

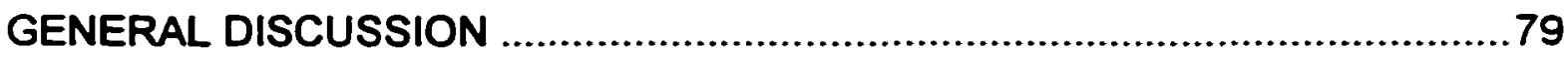

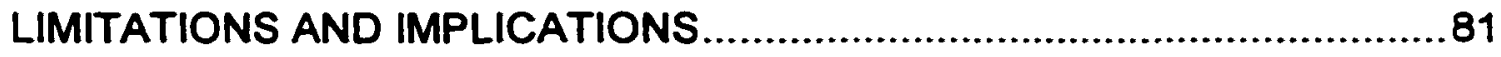

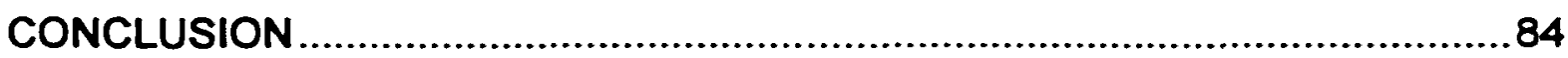

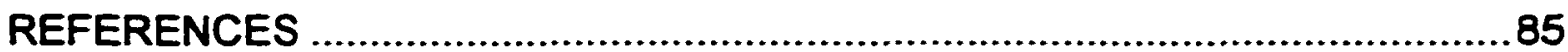

APPENDICES

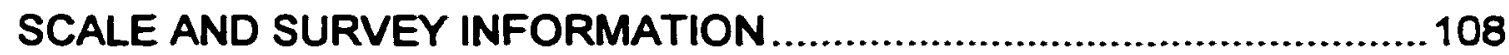

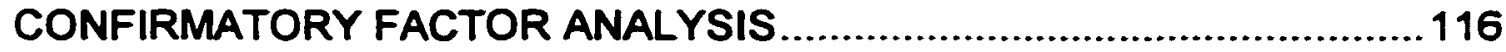

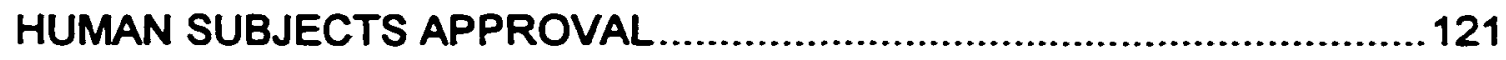

VITA 


\section{LIST OF TABLES}

Table

1. Study 1 Factor Loadings for the Measure of Organizational Inclusion ............41

2. Study 1 Factor Loadings for the Measure of Workgroup Inclusion..................42

3. Means, Standard Deviations, and Correlations for Study 1 .........................43

4. Summary of Maximum Likelihood and Generalized Least Squares

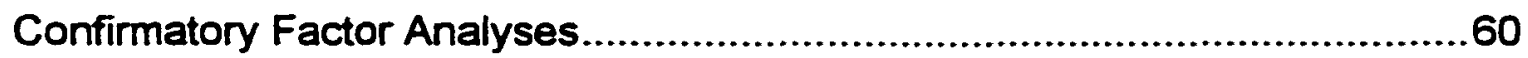

5. Measurement Model Comparisons - Maximum Likelihood..........................62

6. Measurement Model Comparisons - Generalized Least Squares.................62

7. Means, Standard Deviations, and Correlations for Study 2 .......................64

8. Nested Model Comparisons - Maximum Likelihood ...................................65

9. Nested Model Comparisons - Generalized Least Squares.............................65 


\section{LIST OF FIGURES}

Figure

1. Theoretical model of workgroup and organizational inclusion including antecedents and consequences.

2. Structural equation model of the relationships of organizational and workgroup inclusion with antecedent and consequence variables.

Method = Maximum Likelihood.

3 Structural equation model of the relationships of organizational and workgroup inclusion with antecedent and consequence variables.

Method $=$ Generalized Least Squares. 


\section{INTRODUCTION}

"No more fiendish punishment could be devised, were such a thing physically possible, than that one should be turned loose in society and remain absolutely unnoticed by all the members thereof... a kind of rage and impotent despair would ere long well up in us, from which the cruelest bodily tortures would be a relief' (James, 1890, p. 293). James and others (e.g., Festinger, 1950; Maslow, 1954; McDougall, 1908) believed that social needs such as the desire to be recognized and included were basic human necessities. Yet, the reality is that in today's workplace many people feel excluded. For example, women and minorities often feel less than included as full members of the organization, not because of performance deficiencies, but because of differential access to opportunities and an inhospitable climate (Cox, 1994; Gottfredson, 1992; Ibarra, 1993; Kram, 1983; Pettigrew \& Martin, 1989; Shulman \& Darity, 1989).

There is growing recognition that in order to create organizations that are effective with a diverse employee base, the organizational climate must be appropriate (e.g., Miller, 1998; Thomas, 1990; Triandis, Kurowski, \& Gelfand, 1994). And for diverse groups, that means creating an environment that fulfills important social needs of all its members. For this reason, the concept of inclusion is becoming increasingly important to organizational theorists and practitioners. Focusing on fulfillment of important psychosocial needs is an advancement in diversity management because this strategy moves the primary

The model for this dissertation was the Joumal of Applied Psychology. 
focus away from individual differences, which is frequently the aim of the most common diversity strategies (e.g., diversity training). In the words of Thomas, "The wrong question: How are we doing with race relations? The right question: Is this a workplace where 'we' is everyone?" (1990, p. 109). While the importance of making inclusive organizations is being espoused with increasing frequency, the existing literature on inclusion in the organizational context is almost exclusively theoretical; there is an absence of literature on the operational meaning of inclusion or its antecedents and consequences. Further, the nature of inclusion is being discussed without consideration or incorporation of existing empirical or theoretical works.

At the same time, there is growing attention to the characteristics of the exchange relationship between organizations and their employees (e.g., Gould, 1979; Levinson, 1965; Rousseau, 1989). Much of this work focuses on the development of strong attachments by the employees. Mowday, Steers, and Porter (1979), as well as others (e.g., Allen \& Meyer, 1990), have generally defined organizational commitment as an affective or emotional attachment characterized by identification with and involvement in the organization. Social exchange theorists interpret the employment relationship as an exchange, suggesting that employees provide such things as commitment and effort in exchange for tangible (e.g., pay, benefits) and intangible (e.g., psychosocial needs) benefits (Blau, 1964; Eisenberger, Huntington, Hutchison, \& Sowa, 1986; Levinson, 1965; Mowday, Porter, \& Steers, 1982; Rousseau, 1989). At the center of the theory is the norm of reciprocity. As the organization provides benefits from 
its relationship with the employee, the employee is then obligated to reciprocate (Gouldner, 1960). As the benefits increase or decrease, the employee is believed to adjust attitudes and behavior accordingly (e.g., Angle \& Perry, 1983; Armeli, Eisenberger, Fasolo, \& Lynch, 1998; Eisenberger et al., 1986, Eisenberger, Cummings, Armeli, \& Lynch, 1997).

Building an inclusive organization may be best understood from a social exchange ideology. Inclusion is conceptualized as an important psychosocial need and an exchange framework is used to understand the antecedents and consequences. This study draws from a variety of theories and empirical works to develop a foundation for the definition of inclusion in the organizational context. This is followed by an examination of the construct's dimensionality, and a model is developed describing the construct's nomological net. Lastly, the theory is tested empirically.

\section{Background}

In recent years, concern over the implications of an increasingly diverse workforce has grown (Jackson, Stone, \& Alvarez, 1993). Johnston and Packer's (1987) publication of Workforce 2000 emphasized that a very small proportion of the new labor force will come from the "traditional" white male population (only $10 \%$ in 2000), a significant change from only 30 years ago. The workforce will change not only in terms of internal national growth of minority populations, but also in terms of an aging population, increased immigration and employment of people with disabilities, a growth in a youth population for whom English is a second language, and new legal rights for gays and lesbians (Wentling \& Palma- 
Rivas, 1997). The workforce of today also has different demands from past decades. Issues such as work life and personal life balance and meaningfulness are becoming increasingly important. In a survey of practitioners, Hopkins, Sterkel-Powell, and Hopkins (1994) found that the majority of HR directors (89\%) expect their organizations to become increasingly diverse within the next ten years. At the same time, the labor market has steadily tightened, with more organizations competing for fewer available, qualified employees (Jackson \& Alverez, 1993; Johnston \& Packer, 1987).

In the context of an organization's ever increasing demand to become more competitive and efficient, employers are not simply interested in ensuring the legal defensibility of their personnel policies, practices and procedures; rather, they are also interested in "managing diversity" to ensure that all employees reach their full workplace potential (Jackson \& Alverez, 1993; Jackson et al., 1993; Thomas, 1992). Organizations are interested in implementing diversity management initiatives in order to create an environment that supports and retains a diverse workforce while capitalizing on individual differences as a competitive advantage (Cox \& Blake, 1991). Diversity management moves beyond the isolated implementation of programs (e.g. diversity and sensitivity training), to the development of a system wide approach that involves alignment of organizational culture, reward systems, and policies and procedures. Organizations such as Texaco Inc., GTE, and Gannett Corp. Inc. have made great expenditures in implementing diversity management strategies (McCune, 1996). While organizations are hurriedly searching for 
effective practices, there is little concrete guidance on what works best, or at all (Armitage, 1993; Cox, 1990; Wentling \& Palma-Rivas, 1997)

In their comprehensive review of the literature, Wentling and Palma-Rivas (1997) found that organizations take a wide range of approaches and strategies to managing diversity, with diversity training as the most popular overall. While there are few who would argue that the efforts and expenditures have been in vain, most would agree that our current approaches are insufficient. For example, Hopkins et al. (1994) found that $61 \%$ of the Human Resource Directors surveyed felt that they were poorly prepared to manage the growing diversity of their workforce. Rynes and Rosen (1995) surveyed 785 Human Resource professionals about diversity issues and found that only $33 \%$ believed their diversity training programs were successful. They concluded that the adoption and perceived success of diversity initiatives depended on the broader organizational context, such as top management support. The implementation of individual programs helps to a degree, but is not the type of systemic approach needed for large-scale change.

Organizations need to make changes to meet the changing needs of the workforce. Most U.S. corporate cultures were established when the vast majority of workers were European white men (Wentling \& Palma-Rivas, 1997) with Christian religious affiliations. Companies were originally patterned to mirror their values and experiences. Cultures were created to support the workforce's needs as they existed in society at the time; they were created to be inclusive of the majority group. During this early era, most women did not work outside the home 
and minority roles were very limited in the workplace. Although diversity did exist, "those individuals who were different were expected to assimilate into the existing white male culture" (Wentling \& Palma-Rivas, 1997. p. 4).

The effects are still seen in research today. It has been suggested that corporate culture often results in an environment with limited opportunities for the non-white male population (Dunnette \& Motowidlo, 1982). Many factors within the work environment contribute to the experience of exclusion including differential access to opportunities and an inhospitable climate (Gottfredson, 1992; Shulman \& Darity, 1989), factors that are both intentional and unintentional, and both active and passive (Blau, 1977; Jackson, LaFasto, Schultz, \& Kelly, 1992; Miller \& Katz, 1995). Evidence suggests that older workers, women, and ethnic minorities find that they have less access to sources of information and psychiosocial support such as mentors (Cox, 1994; Ibarra, 1993; Kram, 1983; Pettigrew \& Martin, 1989). Further, these groups tend to have fewer developmental and promotional opportunities (e.g., Shulman \& Darity, 1989). Additionally, overt discrimination and sexism can block access to opportunities and be perceived as a sign that some are less welcomed and respected (Hall, 1991; Farmer, 1997). Most importantly, these experiences of exclusion lead to turnover, reduced commitment and job satisfaction, and other negative consequences for both the individual and the organization (Cooper \& Davidson, 1982; Dreher \& Ash, 1990; Farmer, 1997; Greenhaus, Parasuraman, \& Wormley, 1990; Sanchez \& Brock, 1996). 
There is growing consensus that in order to create organizations that are effective with a diverse employee base, the organizational climate must be appropriate (Miller, 1998; Thomas, 1990; Triandis et al., 1994). As noted by Triandis et al. (1994), "managing diversity means changing the culture ... it is more complex than conventional management but can result in more effective organizations" (p. 773). "[The] goal is not to assimilate diversity into the dominant culture but rather to build a culture that can digest unassimilated diversity" (Thomas, 1990, p. 114). Creating inclusive organizations is arguably such a "more complex" approach.

\section{Defining Inclusion in Organizations}

The Inclusion Literature

The idea of inclusion is reflected in a wide variety of literatures, each offering insight into the meaning of the concept. In its basic form, inclusion has been defined as physically including people in organizations and activities where they were previously excluded or underrepresented. Inclusive language has been a topic of interest and research for several decades. Lakoff (1975) noted that "linguistic imbalances are worthy of study because they bring into sharper focus real-world imbalances and inequities" (p. 43). Our societal focus on inclusion likely has its beginning in our educational institutions. In an effort to become inclusive, students with learning disabilities were brought back into mainstream classrooms. "The inclusive movement aimed to ... create schools and other social institutions that are based on acceptance, belonging, and community" (Salend, 1994: 49). The inclusive school has been described as creating an 
environment where every student feels accepted and supported by his or her peers and other members of the school community while having his or her educational and unique sociocultural and psychosocial needs met (Patton \& Townsend, 1997; Stainback \& Stainback, 1990). Similarly, some religious organizations have taken an inclusive approach to building their memberships.

These organizations have used symbolism (e.g., changes in rituals and sermons) and changes in practices (e.g., decision making, increased opportunities for women) to make their organizations more accepting and welcoming to an increasingly diverse population (Becker, 1998; Jacobsen, 1999).

Organizational researchers have adapted some of these same concepts to help bring understanding to the meaning of inclusion in the workplace. The roots of inclusion are reflected in this definition of a "multi-cultural organization:"

The multi-cultural organization reflects the contributions and interests of diverse cultural and social groups in its mission, operations, and product or service; it acts on a commitment to eradicate social oppression in all forms within the organization; the multi-cultural organization includes the members of diverse cultural and social groups as full participants, especially in decisions that shape the organization (Jackson et al., 1992, p. 24).

Theorists have offered general definitions of inclusion in the organizational context, or its opposite, exclusion. Inclusion in the workplace has generally been defined as being fully and respectfully involved in the "life" of the organization (Miller, 1998; Miller \& Katz, 1995; Thomas, 1990). An included person feels welcomed by his or her work group and has a sense of belonging, support of peers, and concern for his or her well-being. Individuals feel valued for their unique contributions to success of the organization and needed for their input, 
skills, and talent. The totally inclusive organization is one where 'we' is everyone (Thomas, 1990). It has been suggested that in an inclusive organization people can "be themselves" at work because they have to suppress far less (e.g., individual differences in opinion, attitudes, preferences). Other suggested characteristics of an inclusive environment include rewards for participation, lack of conflict avoidance, avenues for open communication, support and trust from others, value for differences, protection from emotional harm including offensive language, freedom from injustice, and representation of diverse perspectives in upper management (Miller, 1998; Miller \& Katz, 1995; Thomas, 1990).

Although the term inclusion is relatively new to the organizational literature, the nature of inclusion (fulfillment of important psychosocial needs) is reflected in several existing organizational theories. Additionally, the need for belonging has been the subject of study in a number of literatures. These theories are discussed in the next section followed by a fully developed definition of inclusion in the context of the workplace. This is then followed by development of a model describing the role of inclusion in the organizational context.

Related Theory

Existing organizational thecries and interventions reflect the spirit of creating inclusion. That is, taking actions that include individuals in the power and operations of the organization; actions believed to fulfill important psychosocial needs. For Lawler $(1992,1995)$ the key to creating a high involvement organization that fosters performance and individual satisfaction is to share information, knowledge and power with everyone. He believes that involving 
employees shows a concern for rights of individuals and even personal freedom, recognizing that some individuals may not have this concern or need, and simply want to work and receive little more than pay in return. Involvement, arguably, improves both the quality of life at the individual level and the ability for organizations to quickly react to changing environmental conditions. It has been shown that including employees in operations, such as decision making, increases employee satisfaction and performance, recognizing that the effects are often modest (Cotton, Vollrath, Froggatt, Lengnick-Hall, \& Jennings, 1988; Miller \& Monge, 1986; Wagner, 1994; Wagner \& Gooding, 1987).

Practices such as employee involvement are believed to work as a means of satisfying employees' needs. The "human relations" (Ritchie \& Miles, 1970) school of management focuses specifically on the link between participation and satisfaction (Likert, 1967; McGregor, 1960). "These theorists propose that participation will lead to greater attainment of high-order needs, such as selfexpression, respect, independence and equality, which in turn increase morale and satisfaction" (Miller \& Monge, 1986, p. 730). Although the mediating role of need fulfillment is prominent in organizational theory, it has not been validated empirically in the literature (Brown, 1996).

Scholars have long considered the importance of social needs (e.g., the desire for association, belonging, and inclusion) in understanding human behavior and attitudes (e.g., Batson \& Oleson, 1991; Festinger, 1950; Hill, 1987; Maslow, 1954). Existing empirical evidence "supports the hypothesis that the need to belong is a powerful, fundamental, and extremely pervasive motivation" 
(Baumeister \& Leary, 1995, p. 497). It has been argued that the need to be included in social groups has an evolutionary basis, with membership increasing chances of survival (Baumeister \& Leary, 1995; Grusec, 1991; Leary \& Downs, 1995); "evolutionary pressures may have resulted in a universal need to belong" (Nezlek, Kowalski, Leary, Blevins, \& Holgate, 1997, p. 1235).

Leary and Downs (1995) have argued and demonstrated empirically that inclusion and exclusion by others are primary determinants of psychological wellbeing. For their "sociometer theory," it is believed that individuals monitor the degree to which they are "being included versus excluded by others" (Leary, Tambor, Terdal, \& Downs, 1995, p. 518). Further, it is social inclusion/exclusion that is considered the basis for individuals' psychological well-being. Social exclusion has been related to a variety of effects, including depression, hostility, jealousy, loneliness, decreased state self-esteem, and motivation (e.g., Baumeister \& Tice, 1990; Craighead, Kimball, \& Rehak, 1979; Leary, 1990; Leary \& Downs, 1995; Leary et al., 1995; Leary, Haupt, Strausser, \& Chokel, 1998; Nezlek et al., 1997). Further, empirical evidence suggests that monitoring inclusion is a continuous and often unconscious process (Leary et al., 95; Leary et al., 1998; Nezlek, et al., 1997). This is similar to the Theory of Social Comparison (Festinger, 1950) which asserts that group members have a need to determine their standing within the larger group.

\section{A Conceptual Definition of Inclusion in the Context of Work}

Together, these literatures suggest that inclusion is a basic human psychosocial need with an evolutionary, survival basis. An inclusive organization 
is one that fulfills this need. Inclusion in the workplace is an individual's collective judgment or perception of belonging as an accepted, welcomed and valued member in the larger organization units, such as a work group, department, and overall organization. Although inclusion is a collective judgment developed over time, the monitoring of the environment for indicators of inclusion is a continuous and sometimes unconscious process. Inclusion is considered important because it is a fundamental human need resulting from evolutionary pressures. Fulfillment of this need will lead to a sense of satisfaction with the group (Likert, 1967; McGregor, 1960; Ritchie \& Miles, 1970) and through the norm of reciprocity (Gouldner, 1960) the included individual will respond with attitudes and behavior beneficial to the group. Inclusion is created by environmental features that provide support to the individual, represent acceptance of differences, show concern for each individual's unique needs and well-being, provide protection from emotional and physical harm, act to recognize contributions, and involve individuals in the operations of the organization.

This definition reflects what early theorists (e.g., Festinger, 1950; James 1890; Maslow, 1954) believed were fundamental social needs of all humans. Inclusion is the fulfillment of the human necessity for a sense of belonging, and the need to be recognized and valued by the larger community. If an organization is able to satisfy important social needs (e.g., make every employee feel included and valued) then the organization will have done much to manage diversity, with benefits to the individual and the organization. 


\section{The Role of Inclusion in Organizations}

The model in Figure 1 delineates the role inclusion has in the context of work. The model illustrates how inclusion relates to variables at the workgroup and organizational levels. The following sections discuss the model's components and linkages.

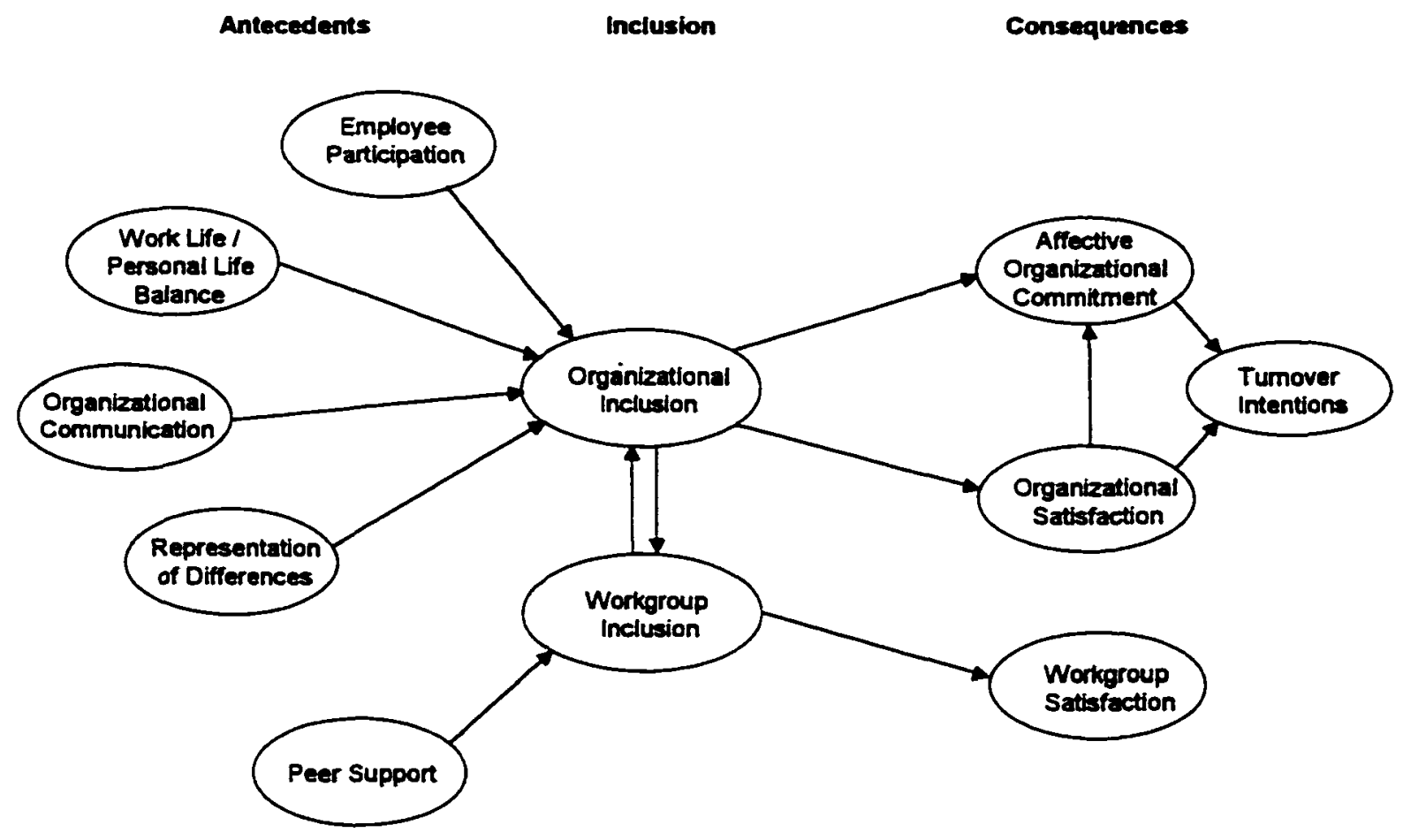

Figure 1. Theoretical model of workgroup and organizational inclusion including antecedents and consequences. 


\section{Multiple Referents for Inclusion}

The model in Figure 1 illustrates the relationship between workgroup inclusion and organizational inclusion. Indirect evidence for the distinction of inclusion perceptions to multiple referents comes from exchange theory. Empirical findings support the assertion that individuals form different exchange relationships within the organizational context. For example, Wayne, Shore, and Liden (1997) found evidence that an individual's exchange relationship with his or her supervisor (leader-member-exchange) was distinct from the exchange relationship with the organization as a whole (perceived organizational support), showing that the two relationships had different antecedents and consequences. Clearly, individuals tend to ascribe human-like traits and attributes to organizations (Levinson, 1965) and consider the personified organization as an entity with which they have a relationship (Eisenberger et al., 1986, 1997; Rousseau, 1989). Similarly, individuals personify other organization groups such as region, department, or workgroup, an assertion supported by limited evidence showing that individuals form exchange relationships with these groups (Hutchison, 1997; Kottke \& Sharafinski, 1988). For example, it has been demonstrated that an individual forms exchange relationships with his or her work team that can be distinguished from relationships with supervisors (i.e., team-member-exchange; Major, Kozlowski, Chao, \& Gardner, 1995). Consistent with theoretical arguments (Blau, 1964; Eisenberger et al., 1986; Levinson, 1965; Mowday et al., 1982; Rousseau, 1989), inclusion is considered part of an exchange relationship such that the individual reciprocates need fulfillment with 
behavior and attitudes beneficial to the entity (or perceived entity) providing the fulfillment.

\section{Antecedents}

Antecedents to inclusion include those factors that make the individual feel welcomed, accepted, and valued by the larger group. Inclusion is created by environmental features that reflect support, acceptance of differences, concern for each individual's unique needs and well-being, protection from emotional and physical harm, and actions that recognize contributions and involve the individual in the operations of the organization. Flexible management practices that allow fulfillment of unique individual needs and practices that share information and power of the organization will be significant predictors of inclusion.

Accommodation of unique needs of the individual, such as needs stemming from physical disabilities, religious affiliation and obligations, or demands from non-work domains will create feelings of being welcomed as a full member of the organization. Factors that recognize individuals' contributions (e.g., reward and recognition programs) will create a sense of being valued. Additionally, features and policies that represent and show respect for individual differences will be a sign that all are welcomed in the organization.

Overtly, inclusion can be influenced through symbolic manifestations that show either respect or disrespect for others (e.g., sexist language, participation in decision making). Covertly, it can be influenced through the inclusion or exclusion of groups from social activities, demeaning jobs for certain individuals, and the apparent refusal by majority members to allow certain groups into 
positions of power. Inclusion perceptions are individuals' macro perceptions developed from micro events. And, although existing at the individual level, these perceptions will be influenced by factors at several levels, such as the individual, workgroup, and organization (Hayes, Bartle, \& Major, 2002).

The effects of environmental factors on inclusion can be best understood through field theory's notion of psychological proximity (Lewin, 1943). Field theory asserts that individuals' reactions to an environment are primarily products of their perceptions of proximal elements in the environmental life space. Elements more distal in one's environment (e.g., organizational features) act as contextual influences and can influence individual reactions directly, particularly if the organizational features are very salient. In general, however, aggregate features of the environment exert an indirect influence on individuals by shaping perceptions of more proximal elements (Mathieu, 1991).

Organization-wide policies, practices, and procedures send implicit and explicit messages to employees about the organization's attitudes toward employees. For example, the existence of an affirmative action policy, a family leave policy, a sexual harassment training program, and employee grievance process are examples of policies that may influence these perceptions. Likewise, an organization's compensation, promotion, and hiring systems may be viewed as exclusive if members of identifiable groups (e.g., part-time workers, women, minorities) are consistently underpaid, passed over for promotions, or simply not hired. Research demonstrates that policies and procedures can impact 
perceptions (e.g., Kravitz, Harrison, Turner, Levine, Chaves, Brannick, Denning, Russell, \& Conrad, 1996; Nacoste, 1987; Schappe, 1996; Westin, 1992).

The effect of policies, practices, and procedures on inclusion are complicated by the manner in which they are presented, displayed, or communicated within the organization (Murrell, Dietz-Uhler, Dovidio, Gaertner, \& Drout, 1994). Additionally, these factors may have an indirect effect by influencing other features. For example, Konrad and Linnehan (1995) compared the effects of two distinct groups of human resource practices, those that explicitly included group membership (e.g., demographics) in decisions (termed identity-conscious structures) and those that did not (termed identity-blind structures). They found that only identity-conscious structures were associated with higher levels of employment status for minority groups (e.g., women in executive management). However, as a corollary, they also found that these structures were often unpopular with minority and majority groups because decisions were perceived to be based on group membership and not on merit. In contrast, identity-blind structures were generally perceived as fair by members of all groups, but as many have argued, do not facilitate altering the demographic mix in top management to reflect the mix present in today's diverse work force (e.g., Johnston \& Packer, 1987). The apparent homogeneity of management may be interpreted to mean that only those individuals with certain characteristics or traits will advance in the organization. This research punctuates the complex manner in which organizational factors may influence inclusion perceptions. 
While organizational factors exert a distal and mostly contextual influence, work group factors have a more direct or proximal effect on individuals' perceptions (Lewin, 1943). Work groups are collectives of individuals defined by organizational structure (e.g., functional area) and job requirements (e.g., production team). Each work group has its own unique set of characteristics (e.g., supervisor, norms, co-worker behaviors) which have a strong influence on perceptions due to their proximity (Schneider \& Reichers, 1983). And, perhaps, the most significant factor that influences perceptions is an individual's personal experiences within the organization: How the individual is personally treated will be the most psychologically proximal aspect of the environment, and therefore, the most salient to the individual. A growing body of evidence demonstrates the significant impact of relevant personal experiences on work related attitudes and behavior (e.g., Schneider, Swan, \& Fitzgerald, 1997). For example, Newell, Rosenfeld, and Culbertson (1995) found that women who reported being sexually harassed perceived less opportunity in the Navy than did women who had not been harassed. While all of the women in this study were influenced by the same organizational factors (i.e., the Navy's sexual harassment policy), the individual experience of being sexually harassed distinguished women's perceptions of opportunities in the organization as a whole.

Field proximity is not sufficient to understand the influence of antecedents on inclusion. Because inclusion perceptions are formed for different referent groups within the organization, in addition to determining the psychological proximity of a feature, source attributions must also be considered. That is, a 
feature may be attributed to the organization, the region, the department, or the workgroup, with the direct influence contingent on that attribution. For example, an organizational policy designed to protect the rights of individuals, such as rules forbidding sexist language, will likely influence organizational inclusion. However, when the work group openly and continuously violates the policy, some individuals within the group whose gender is the subject of ridicule (among others) will have lowered perceptions of workgroup inclusion. Further, if the behavior continues to go unpunished by the organization, there will likely be a negative impact on organizational inclusion.

In general, there will be an upward influence between inclusion referents. Features attributable to the workgroup will have a direct influence on workgroup inclusion. But, because the workgroup will be viewed as an agent of the organization, there will be an indirect influence through the influence of workgroup inclusion on organizational inclusion. That is, behavior of organizational members carried out on the part of the organization are considered indicative of the organization and not necessarily attributed solely to the intent of the individual (Levinson, 1965). This attribution is supported by the belief that the organization is responsible for actions of its agents because the organization prescribes behavior through policies, roles, etc., and the organization has power to influence employees. Exceptions include behaviors carried out by individuals or groups that are perceived as inconsistent with or not specifically prescribed by the organization, such as helping co-workers with nonwork related social or personal activities (Turner, Hayes, Bartle, \& Green, 1999). 
In support of an upward influence is evidence that the relationship between supervisors and employees is positively related to employees' perceived relationship with the personified organization. However, there is also evidence that such relationships have a reciprocal influence. In the Wayne et al. (1997) study, there was a reciprocal association between an individual's exchange relationship with his or her supervisor (leader-member-exchange) and the exchange relationship with the organization as a whole (perceived organizational support), with leader-member-exchange having a larger influence on perceived organizational support than vice-versa, indicating that the upward influence was the strongest. The authors note that organizational support could have an influence on leader-member-exchange because employees that feel they have the support of the organization may be more likely to develop positive, supportive relationships with their supervisors (Wayne et al., 1997). Similarly, it may be that individuals who feel included by the organization may feel more welcomed in any subgroup of the organization.

Hypothesis 1: There will be a reciprocal, positive relationship between workgroup inclusion and organizational inclusion; however, the influence of workgroup inclusion on organizational inclusion will be greater than the opposite.

Specific Antecedents

Representation of differences. According to Miller (1998), the inclusive organization has a representation of diverse perspectives in management, suggesting that the representation of differences in senior leadership and other 
positions of authority will influence perceptions of inclusion. It has been argued that the representation of minorities in positions of authority affects the perceptions of individuals at lower levels about possibilities for advancement (Ely, 1994; Hayes et al., 2002). For example, employees within an organization may think a "glass ceiling" exists if there are no women in top management. This perception of a barrier for women or minorities will have a negative influence on inclusion by making them feel less welcomed or included as full members. Riordan and Shore (1997) studied perceptions in an organization composed of 34\% Africans American employees with an almost exclusively Caucasian executive management group. African American employees perceived fewer opportunities for advancement than did Caucasian employees. Research suggests that these perceptions may sometimes be accurate. Greenhaus et al. (1990) showed that being an ethnic minority in an organization directly affected job mobility beyond that which could be explained by education and career strategizing methods. Representation of diversity in management (e.g., perspectives, personality, race, sexual orientation) demonstrates that the organization is welcoming to a diverse group of individuals, influencing inclusion perceptions for all employees.

While researchers have generally focused on the influence of racial and gender diversity in management, representation of differences goes beyond demographic composition. A truly inclusive organization is able to accept and provide for the unique sociocultural needs of all its members. This means recognizing and celebrating different religious affiliations, people from all levels 
and positions in the organization, and a wide range of events (e.g., work anniversaries, birthdays, weddings), just to name a few. Together, representation of diversity in management and actions that recognize and celebrate differences send the message that individual differences are not only accepted, but welcomed and valued by the organization.

Hypothesis 2: Representation of differences will have a positive influence on organizational inclusion.

Organizational communication. Information provided by different organizational sources influences employees in many ways, such as building task knowledge and affecting socialization for newcomers (Ostroff \& Kozlowski, 1992; Morrison, 1993a, 1993b). Social information processing theory suggests that communications from organizational members are used by employees to form opinions about their relationship with the organization (Salancik \& Pfeffer, 1978). Although all sources of communication (e.g., management, workgroup, supervisor) influence attitudes, communication from senior management is considered particularly important for building strong attachments (Allen, 1992; Cheney, 1983; DeCotiis \& Summers, 1987; Mathieu \& Zajac, 1990; Putti, Aryee, \& Phua, 1990). These communications carry social cues about how the organization views employees, which, over time, influence employees' perceptions and attitudes (Allen, 1992; Salancik \& Pfeffer, 1978).

One type of communication from senior management is intended to keep employees informed about the organization's vision, goals, objectives, and actions. Proactively informing all employees about the organization's activities 
sends the message that each individual is a part of the overall organization and, as such, should be informed with open, honest communications. As a result, employees will feel involved in the organization and included in its activities. This is consistent with arguments and limited empirical evidence that certain communications influence employees sense of membership in the organization (Allen, 1992; Cheney, 1983; DeCotiis \& Summers, 1987; Mathieu \& Zajac, 1990; Putti et al., 1990). For example, Allen (1992) compared two types of communication (perceived quality such as timeliness and clarity, and perceived communication relationship such as sincerity and openness) from three sources (top management, co-workers, and supervisor). While all three sources were positively correlated with organizational commitment, the top management communication relationship was the strongest predictor of employee attachment to the organization. For the current study, it was expected that employees' perceptions about the clarity, openness and honesty of communications about the organization's vision, goals, and objectives would build inclusion by making employees feel more involved in the organization.

Hypothesis 3: Perceived openness and honesty of senior management's communications regarding organizational vision, goals, and objectives will have a positive influence on organizational inclusion.

Work life and personal life balance. Social support is generally conceptualized in one of two ways. support characterized as emotional support consisting of listening and empathizing or instrumental support consisting of tangible assistance aimed at solving problems (Adams, King, \& King, 1996; 
Beehr \& McGrath, 1992; Goldsmith, 1992; House, 1981; Mclntosh, 1991).

Researchers usually consider benefits of social support from work-related sources as having the ability to reduce stress (e.g., Beehr, 1985, 1995; House, 1981). However, such support may also create feelings of inclusion, through both its instrumental and psychosocial benefits, by creating perceptions of caring for one's well-being. Additionally, such support shows concern for the whole person and not just the skills and talents that directly benefit the organization.

Work life and personal life balance issues are usually approached from the perspective of conflict that occurs as a result of competing work and family demands, conflict creating stress that influences the individual both physically and psychologically (e.g., Burke, 1988; Frone, Russell, \& Cooper, 1992; Greenhaus \& Beutell, 1985; Greenhaus \& Parasuraman, 1987; Kopelman, Greenhaus, \& Connolly, 1983). It is recognized that demands of family can interfere with work involvement (e.g., accomplishing daily work tasks and putting in overtime) and work demands can interfere with family involvement (Frone et al., 1992; Greenhaus \& Beutell, 1985; Netemeyer, Boles, \& McMurrian, 1996). One line of research has investigated the role of social support in work life and personal life balance issues (also called work-family balance or conflict). For example, Adams et al. (1996) found that social support provided by one's family was associated with reduced levels of family interfering with work and increased involvement in the family. Similarly, instrumental and emotional support provided from the work environment may contribute to inclusion. 
When the work environment recognizes an individual's non-work demands and provides emotional and instrumental assistance in balancing those demands, the individual will perceive that the organization cares for his or her well-being, resulting in increased inclusion in the organization. When the environment does not provide such support, the individual is not free to share outside demands in an attempt to either find alternative paths to meet demands or needed emotional support to cope with the related stress. In effect, the nonwork part of the individual is not welcomed or included in the work place. In this way, the whole of the individual is not included or does not "belong" in the organizational context, therefore, reducing perceived inclusion. Consistent with this argument, Wentling and Palma-Rivas (1997) comprehensive review of the diversity management literature identified several factors likely to create exclusion and/or inhibit inclusion, including the balancing of work and family and an unsupportive work environment.

Empirical evidence provides indirect support for these assertions with most research focused on organizational initiatives intended to provide instrumental support. For example, research has shown that the availability of work-family benefits (e.g., family leave, dependent care leave) are associated with increased organizational attachment, suggesting that such benefits represent a general concern for employees (e.g., Grover \& Crooker, 1995; Guzzo, Noonan, \& Elron, 1994; Thompson, Beauvais, \& Lyness, 1999). Lambert (2000) showed that employees' assessments of the usefulness of work-life balance benefits provided by the organization (e.g., support for childcare, tuition 
reimbursement) were positively related to perceptions that the organization was concerned for employees' well-being. A few studies have focused on the benefits of a family oriented culture. Thompson et al. (1999) found that perceptions of a family supportive organizational culture were predictive of worker attitudes, above and beyond the availability of work-family benefits. Perceived organizational advocacy for work-family balance and sensitivity to family responsibilities (e.g., "In general, managers in this organization are quite accommodating of family-related needs") were predictive of decreased intentions to leave the organization.

In the current study, the focus is on what Kahn (1990) refers to as a flexible and supportive management. That is, leadership is flexible about performance of job duties, tangible support is available in the form of assistance with job duties, and emotional support is created from an environment that makes the individual feel open to discuss outside demands and difficulties with one's boss and co-workers. Instrumental support can come in several forms, including programs such as leave for care of ill family members, flexible management practices that support individuals as they attempt to balance the demands of their lives, and coworkers who are available to help fulfill job duties. In sum, it is argued, and supported to some degree by empirical evidence, that perceived instrumental and emotional support for work life and personal life balance creates inclusion by showing a general concern for the individual's wellbeing and making the individual feel welcomed to bring his or her whole self to 
work. The included individual believes the organization values the whole person, not just the extent to which he or she can fulfill job duties.

Hypothesis 4: Perceived support of work life and personal life balance will have a positive influence on organizational inclusion.

Peer support. Besides social support with work life and personal life balance, general emotional support from coworkers and others has been considered an important environmental factor. Peer relationships have been considered important to the personal and career growth of individuals, providing both career-enhancing and psychosocial functions (Kram \& Isabella, 1985). Within the psychosocial function, peers are able to provide confirmation to each other through the sharing of perceptions, values, and beliefs related to their work lives. In addition, peers can provide emotional support by listening and counseling each other during periods of transition and stress (Kram \& Isabella, 1985). The availability of such support will help satisfy the need for belonging that is central to inclusion. Because such support is specific to the work group, it is likely to have the greatest direct impact on workgroup inclusion. That is, coworkers providing emotional support are not necessarily acting according to roles or policies prescribed by the organization, a connection arguably necessary for actions of individuals to be attributed to actions of the personified organization (Levinson, 1965). In support of this is the finding that employees differentiate support from the personified organization and support received from their immediate supervisor (Hutchison, 1997; Kottke \& Sharafinski, 1988). Additionally, evidence suggests that supervisors, when rating performance, are able to 
distinguish between behaviors that are and are not specifically prescribed by roles (Turner et al., 1999).

Hypothesis 5: Perceived social support from the immediate workgroup will have a positive influence on workgroup inclusion.

Employee participation. Miller and Katz (1995) suggested that included individuals are encouraged to participate in decisions that impact their work: "Diversity describes the make-up of a group. Inclusion describes which individuals are allowed to participate" (Miller, 1998, p. 151). Sharing of power has been argued to be a central feature of an inclusive organization (e.g., Prasad, 2001). As discussed, practices such as employee involvement are believed to work as a means of satisfying employees' needs with need satisfaction mediating the relationship between involvement and outcomes such as satisfaction with the organization (Lawler, 1992, 1995; Likert, 1967; McGregor, 1960; Ritchie \& Miles, 1970). Involvement has been operationalized in a number of ways, with participation in decision making as one of the most common. As originally defined by Vroom (1960), "the amount of participation of any individual will be the amount of influence he has on the decisions and plans agreed upon" (p. 9).

Brown's (1996) meta-analysis showed that participation in decision making was a significant antecedent to a number of outcome variables including satisfaction and job involvement, relationships consistent with theoretical arguments (Lawler, 1992). While participation has been linked to a number of outcomes, its ability to satisfy important needs (need fulfillment as a mediator) has not been empirically demonstrated (Brown, 1996). Consistent with theoretical arguments (e.g., Miller 
\& Katz, 1995; Prasad, 2001), participation is expected to create perceptions of inclusion with inclusion mediating the relationship between participation and outcomes.

The level or extent of participation will depend on organizational policy or culture. However, the actual practice of participation will most often be executed by supervisors or managers and involve interactions between employees and their supervisors and coworkers. Because behavior of organizational members carried out on the part of the organization is considered indicative of the organization and not the individual (Levinson, 1965), the practice of participation will be perceived as an organizational level practice or policy. As such, the influence will be on organizational inclusion, an assertion consistent with findings by Hutchison and Garstka (1996) showing a positive relationship between participation in goal setting during the performance appraisal process and attitudes towards the organization as a whole.

Hypothesis 6: Perceived ability to participate and influence decisions that directly affect one's work will have a positive influence on organizational inclusion.

\section{Consequences}

As discussed, there is growing evidence that environmental factors and interventions do not directly affect important outcomes such as performance, attitudes, and turnover. Rather, it is believed these factors, such as management practices and culture, work to satisfy important individual needs, and those needs drive outcomes (Likert, 1967; McGregor, 1960; Miller \& Monge, 1986; Ritchie \& 
Miles, 1970). Consistent with social exchange ideology and the norm of reciprocity, fulfillment of important psychosocial needs should motivate positive work-related behavior and attitudes. Failure to reciprocate is believed to produce discomfort, motivating the employee to reduce the discomfort by reciprocating. However, the strength of the reciprocation obligation would depend on the value placed on psychosocial needs (Gouldner, 1960) and the desire to have the needs satisfied within the context of work. Further, studies have added to Gouldner's (1960) tenet of reciprocation by showing that reciprocation obligation is to a specific entity, such as supervisor, coworkers, or organization. For example, Wayne et al. (1997) showed that perceived organizational support was related to commitment to the organization whereas leader-member-exchange was predictive of doing favors for the supervisor. Similarly, reciprocation for inclusion will be in the form of behavior and attitudes that are of direct benefit to the entity that fulfilled the need. Organizational inclusion will have the greatest direct influence on factors that most directly benefit the organization, such as organizational commitment, satisfaction with the organization, and turnover. Workgroup inclusion will be reciprocated with behaviors that benefit the group, such as helping co-workers, satisfaction, and commitment to the group. (Note that helping and workgroup commitment were not measured in the current study.)

While reciprocation is believed to be both behavioral and attitudinal, behavioral reciprocation for inclusion is likely more strongly related to withdrawal behaviors and citizen behaviors, such as helping coworkers, rather than task 
performance. Reciprocation may impact task performance by increasing motivation. However, reciprocation will have little to no influence on other factors that account for task performance such as skills, knowledge, and resource availability. Similarly, research on employee participation practices has consistently shown participation to be more strongly related to satisfaction than performance (Miller \& Monge, 1986), a finding consistent with theoretical arguments (Likert, 1967; McGregor, 1960, Ritchie \& Miles, 1970). Inclusion will likely have its greatest influence on attitudes and withdrawal behavior. Specific Consequences

Affective organizational commitment. As discussed, affective organizational commitment is generally defined as an "emotional attachment to the organization such that the strongly committed individual [is believed to identify] with, is involved in, and enjoys membership in the organization" (Allen \& Meyer, 1990, p. 2). Highly committed employees are expected to remain with the company because they want to. As already noted, satisfaction of needs is considered the basis for building strong affective attachments to the organization (Meyer, Allen, \& Smith, 1993; Mowday et al., 1982). As predicted by exchange theory, empirical evidence supports the assertion that employees reciprocate benefits derived from their relationship with the organization with increased organizational commitment (Eisenberger, Fasolo, \& Davis-LaMastro, 1990; Guzzo et al., 1994; Hutchison \& Garstka, 1996; Jones, Flynn, \& Kelloway, 1995; Settoon, Bennett, \& Liden, 1996; Shore \& Tetrick, 1991; Wayne et al., 1997). 
Hypothesis 7: Organizational inclusion will have a positive influence on organizational commitment.

Workgroup and organizational satisfaction. As discussed, a number of theories assert that an individual's satisfaction reflects the extent to which a job, work group, organization or other definition of the environment (depending on the focus of the satisfaction) provides experiences and outcomes that satisfy important needs (Likert, 1967; McGregor, 1960; Ritchie \& Miles, 1970). For example, it is believed that organizational factors such as participation lead to attainment of needs which, in turn, increase morale and satisfaction (Miller \& Monge, 1986). This is similar to personality research showing that people are happiest when their needs are met by environmental factors (e.g., Diener, Larsen, \& Emmons, 1984).

Hypothesis 8: Organizational inclusion will have a positive influence on organizational satisfaction.

Hypothesis 9: Workgroup inclusion will have a positive influence on workgroup satisfaction.

Turnover intentions. Turnover intentions represent the ultimate outcome of the affective relationships shown in Figure 1. Empirical evidence supports a significant, positive relationship between turnover intentions, the attitude, and actual turnover, the behavior (Hom, Caranikas-Walker, Prussia, Dickey, Anderson, \& Griffeth, 1991; Mobley, Griffeth, Hand, \& Meglino, 1979; Williams \& Hazer, 1986). It is generally accepted and well supported that intention cognitions mediate nearly all attitudinal linkage with turnover (Tett \& Meyer, 
1993). In application, satisfaction and organizational commitment are frequently included as two important indicators and determinants of employee turnover and considered to mediate the relationship between environmental factors and turnover (Clegg, 1983; Lance, 1991). Further, satisfaction and organizational commitment relate independently and jointly to turnover (Hayes, 1997; Tett \& Meyer, 1993), with satisfaction and organizational commitment also sharing a reciprocal relationship. However, if a reciprocal relationship were specified, the model would violate the rank condition and the model would not be identified.

The rank condition rule states that each dependent variable in a feedback loop (e.g., organizational inclusion and workgroup inclusion) must have a unique set of predictors coming in from outside the loop (Bollen, 1989). For example, organizational inclusion has four predictors coming into the loop, while workgroup inclusion has only one predictor. In contrast, both organizational commitment and organizational satisfaction have only a single predictor coming in, and that predictor is the same for both. Therefore, if a reciprocal relationship were specified, it would create identification failure. To reconcile this issue, only the path from organizational satisfaction to organizational commitment was specified. This is consistent with evidence indicating that satisfaction is a precursor to organizational commitment rather than the opposite (Mathieu \& Zajac, 1990; Williams \& Hazer, 1986).

Hypothesis 10: Organizational commitment and organizational satisfaction have a negative influence on tumover intentions and mediate the relationship between other factors and turnover intentions. 
Hypothesis 11: Organizational satisfaction has a positive influence on organizational commitment. 


\section{STUDY 1}

Testing the proposed model of inclusion (i.e., Hypotheses 1 through 11) required the creation of several new measurement instruments, including measures to assess workgroup and organizational inclusion. Because of this, it was considered appropriate to conduct a pilot test of the survey instrument (Study 1). Study 1 was conducted as an exploration of the measurement model. Study 2 involved confirmation of the measurement model and tests of the proposed latent variable model (i.e., Figure 1). Study 1 included all measures used in Study 2 except for the items assessing workgroup satisfaction. These items were added in Study 2 . In addition to exploring the measurement model, data collected for Study 1 were used to perform a preliminary test for perceptpercept bias. Both studies employed a self-report questionnaire as the sole data source. Such data have been criticized and faulted for percept-percept inflation. This point will be addressed in discussion of results for Study 1.

\section{Method}

\section{Participants}

Undergraduate students at a mid-Atlantic university were recruited by offering the incentive of extra credit toward course work. All 418 participants (114 males and 304 females) were employed in a position requiring them to work with coworkers at the time of participation. The average age of the respondents was $23.3(\underline{S D}=6.84)$ with an average of 4.0 years $(\underline{S D}=5.22)$ of full-time work experience. Participants worked in a variety of occupations and industries, including food service (18.7\%), customer service (16.3\%), sales and marketing 
(13.6\%), government $(9.6 \%)$, human services $(9.6 \%)$, education $(8.9 \%)$, manufacturing $(7.6 \%)$, finance $(6.0 \%)$, entertainment $(4.8 \%)$, and miscellaneous other areas $(4.9 \%)$.

Sample Size

The objective was to obtain a sample size sufficient to support exploratory factor analysis on the measurement model. Using a general rule of thumb, the goal was to obtain a minimum of five participants per survey item. With a total of 64 observed variables (i.e., survey items), a minimum sample of 320 was needed.

\section{Measures}

Measures used in the current study were obtained in several ways. Some of the measures were original scales created for this study, others were created for this study, but partially based on existing measures, and some were adopted from the extant literature with few or no modifications. The measures are described below. All scales used the same response format with respondents indicating the extent of their agreement with each item on a 5-point Likert-type scale ( 1 = strongly disagree, 5 = strongly agree).

The first group of measures was created for use in this study. For these constructs, appropriate measures did not exist in the literature.

Organizational inclusion. Five items were generated to assess perceptions of belonging as a welcomed member in the organization as a whole and being valued by the organization. 
Workgroup inclusion. For assessing perceived workgroup inclusion, six items were created. These items focused on perceptions of belonging to one's immediate workgroup as a welcomed member and being valued by that group.

Representation of differences. A nine-item measure was developed to assess the presence of symbolic manifestations that reflect respect and acceptance for differences. The items assessed perceived representation of differences in senior management, recognition and celebration of different religiously affiliated holidays, recognition of individuals from different organizational positions, and celebration of personal events (e.g., birthdays, weddings).

For this next group of measures, existing scales did not cover the necessary domain space for the current focus. New measures were developed based partially on existing measures.

Organizational communication. Several scales exist for the measurement of organizational communication. For example, Allen's (1992) measure focuses on perceived quality of communication (e.g., sincerity, openness) between leadership and other employees. However, the existing measures do not reference content of interest in the current study. Therefore, a six-item measure was developed to assess perceived openness and honesty of senior management's communications regarding organizational vision, goals, and' objectives.

Work life and personal life balance support. While a number of measures exist related to work life and personal life balance, none specifically address the 
current focus, although a few partially covered the necessary domain (e.g., Thompson et al., 1999). An eight-item measure was developed with items selected to tap both dimensions of social support, emotional support consisting of listening and empathizing and instrumental support consisting of tangible assistance aimed at solving problems (Adams et al., 1996; Beehr \& McGrath, 1992; Mclntosh, 1991). Items addressed the extent to which support for non-work activities was provided by supervisors, co-workers, and the organization as a whole.

Organizational satisfaction. Although a number of measures exist that assess different aspects of satisfaction in the context of work (e.g., Smith, Kendall, \& Hulin, 1969), these measures do not specifically focus on satisfaction with the overall organization. Therefore, a four-item measure was developed.

Peer support. While a number of measures of social support exist, none specifically addressed the perceived availability of emotional support provided by individuals within the organization, expressly focusing on support from the immediate workgroup. For example, Sarason, Levine, Basham, and Sarason's (1983) measure, the Social Support Questionnaire, assesses the number of supports available to an individual and general satisfaction with available social support. Based on the current conceptualization of social support and partially using content covered in existing measures (Adams et al., 1996; Beehr \& McGrath, 1992; Mclntosh, 1991; Sarason et al., 1983), a nine-item measure was developed. 
For the following constructs, appropriate measures existed in the literature and were adopted for use in the current study. Any changes to the existing scales are described.

Employee participation. A seven-item measure was used to assess an employee's perceived level of influence on decisions affecting his or her work. Four-items were adapted from Vroom (1960) and three items were developed for this study.

Organizational commitment. Attachment was assessed with the six-item affective commitment scale from Meyer et al. (1993). This measure has been reported to have satisfactory internal consistency reliability (alpha $=.85$ ) and evidence supports this measure as one of the independent components of organizational commitment (Meyer et al., 1993; Shore \& Wayne, 1993).

Turnover intentions. There exist a number of measures of employee turnover intentions. These measures usually contain one to four questions asking if the individual is either currently looking for a new job or has plans to change jobs in the future (e.g., Rosin \& Korabik, 1995; Tett \& Meyer, 1993; Thompson et al., 1999). Based on these existing surveys, a four-item measure was adapted to assess the likelihood of leaving the organization in the next one to two years. Procedure

Eligible students responding to a request for participants were provided a survey packet. The request described the study as an examination of work related attitudes. The survey packets consisted of a cover letter that included an informed consent statement, the survey, demographic questions, and a 
debriefing statement. The students were allowed to take the survey packets and return them at a later date. A total of 540 packets were distributed creating a return rate of $77 \%$.

The beginning of the survey included the following directions to participants:

Listed below are a series of statements about work experiences and attitudes. While responding to each statement, think about the company or organization that you are currently working for. Please answer honestly to all questions and know that your responses will remain completely confidential.

When a question refers to the 'organization' or 'company, please think of the company as a whole.

When a question refers to your 'management' or 'senior management,' please think of those persons at the highest levels of management in the company.

When a question refers to your 'boss' or 'supervisor,' please think of your immediate boss.

When a question refers to your 'co-workers' or 'workgroup,' please think of those people you work most closely with.

Results for Study 1

The objective of Study 1 was measure development, with the goal of making changes to improve the measurement model fit for use in Study 2. Because such a large percentage of the measures and individual items were newly constructed, the approach for Study 1 was exploration of the measurement model. Although exploratory factor analyses were used, labeling this approach exploratory is somewhat misleading because the results were tested against the proposed, hypothetical model. Anderson and Gerbing (1988) called this a "restricted analysis" indicating that it falls somewhere between an exploratory factor analysis and a confirmatory factor analysis. The current analyses were 
intended to provide evidence for both the unidimensionality of each factor and to assess the uniqueness of each factor's domain space relative to the other factors (i.e., item cross-loadings). The resulting measurement model structure will be confirmed as part of Study 2.

Responses to the survey were first analyzed by the method of principalcomponents analysis with varimax rotation. Because the focus of this study was on the construct of inclusion, intrascale analyses were performed on the measures of workgroup and organizational inclusion. As shown in Tables 1 and 2 , analyses on both the organizational inclusion and workgroup inclusion items produced unidimensional solutions. In these first analyses, the proposed organizational inclusion component accounted for $65.5 \%$ of the total variance and the proposed workgroup inclusion component accounted for $64.0 \%$ of the total variance.

\section{Table 1}

Study 1 Factor Loadings for the Measure of Organizational Inclusion

\begin{tabular}{lc}
\hline \multicolumn{1}{c}{ Statement } & $\begin{array}{c}\text { Factor } \\
\text { loading }\end{array}$ \\
\hline I am included as a full member of this organization & .87 \\
The organization lets me know I am one of its valued & \\
members & .82 \\
I rarely feel excluded by the organization & .80 \\
I feel like I belong at this company & .78 \\
I am fully involved in the "life" of my company & .77 \\
\hline
\end{tabular}


Table 2

Study 1 Factor Loadings for the Measure of Workgroup Inclusion

\begin{tabular}{lc}
\hline \multicolumn{1}{c}{ Statement } & $\begin{array}{c}\text { Factor } \\
\text { loading }\end{array}$ \\
\hline I am included as a full member of my workgroup & .85 \\
My work group includes me as one of its full members & .83 \\
I am accepted by my co-workers & .81 \\
My work group makes me feel welcomed & .81 \\
I rarely feel excluded by my co-workers & .77 \\
I feel valued by co-workers for being me & .73 \\
\hline
\end{tabular}

Next, an interscale analysis was performed on all 64 survey items. Initial results indicated a latent structure consisting of ten components. The analysis used an eigenvalue cutoff of 1.0. Components with eigenvalues less than 1.0 were considered to contain more than an acceptable level of error. These ten components were consistent with the ten variables specified by the measurement model. However, results also indicated the need for improvement with ten items having unsatisfactorily low loadings on the intended component (e.g., less than .50) and/or high cross-loadings on different components (e.g., greater than .35). These ten items were removed ( 1 employee participation item, 3 peer support items, 2 work life and personal life balance items, 3 representation of differences items, and 1 turnover intentions item). The analysis was repeated after removing these items and results indicated that no further improvements were necessary (see Appendix A, Table A1 for results of the final analysis). The final analysis accounted for 70.0 percent of the total variance. Additionally, internal consistency of each scale was assiessed using Cronbach's alpha estimate of internal consistency reliability. Both overall scale reliability estimates and individual total 
item correlations were reviewed. All estimates were satisfactory and the results are presented in Table 3. Table 3 also provides descriptive statistics and interscale correlations.

Table 3

Means, Standard Deviations, and Correlations for Study 1

\begin{tabular}{lllllllllllll} 
Variable & $M$ & $S D$ & 1 & 2 & 3 & 4 & 5 & 6 & 7 & 8 & 9 & 10 \\
\hline
\end{tabular}

1. Organizational Inclusion

2. Workgroup Inclusion

$3.570 .98 \quad(.87)$

3. Peer Support

$\begin{array}{llll}4.26 & 0.75 & .47 & (.88)\end{array}$

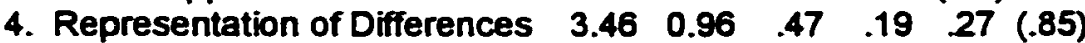

5. Organizational Communication

6. Work-life Balance

$\begin{array}{lllllll}3.58 & 1.00 & .51 & .21 & .21 & .53 & (.90)\end{array}$

7. Employee Participation

$\begin{array}{llllllll}3.61 & 0.95 & .43 & .23 & .27 & .44 & .53 & (.83)\end{array}$

8. Organizational Commitment

9. Organizational Satisfaction

$\begin{array}{lllllllll}3.34 & 1.06 & .54 & .32 & .28 & .43 & .49 & .53 & (.91)\end{array}$

9. Organizational Satis

$\begin{array}{llllllllll}2.78 & 1.10 & .63 & .31 & .38 & .48 & .43 & .33 & .48 & (.90)\end{array}$

$\begin{array}{lllllllllll}3.72 & 1.09 & .63 & .29 & .30 & .55 & .57 & .56 & .51 & .61 & (.93)\end{array}$

$\begin{array}{llllllllllll}3.53 & 1.34 & -.38 & -.17 & -.12 & -.25 & -.26 & -.23 & -.31 & -.45 & -.42 & (.88)\end{array}$

Note: All rs $>.10, p<.05$. Figures in parentheses are internal consistency reliability estimates. $n=417$ for peer support, $n=413$ for tumover intentions, and $n=415$ for the remaining scales.

\section{Discussion of Study 1}

The primary purpose of Study 1 was exploration of the measurement model to be used in Study 2 . The results of Study 1 supported the proposed measurement model. Most scale items loaded on the intended dimension and cross loadings were generally acceptable. Of specific importance, results support workgroup inclusion as a separate construct from organizational inclusion; individuals were able to discriminate their perceptions of inclusion in the immediate workgroup from their perceptions of inclusion to the organization as a whole. Further, inclusion perceptions were distinct from attitudes such as 
satisfaction. Although results were generally supportive, some adjustments were made to improve the measurement model.

Percept-percept Inflation

Percept-percept inflation is defined as artificial elevation of bivariate relationships (e.g., covariation) resulting from the use of self-report data as the sole source of data, as is the case with the current study. Critics have argued for the existence of such inflation and general condemnation of self-report questionnaires as the sole source of data collection (e.g., Campbell, 1982). In contrast to this criticism, empirical evidence has been mixed and highly contested (e.g., Spector, 1987; Williams, Cote, \& Buckley, 1989). The metaanalysis of over 581 articles performed by Crampton and Wagner (1994) indicated that, while bias from self-report data does exist, the prevalence of percept-percept inflation is not as widespread as others have suggested, and the results "challenge the validity of general condemnations of self-report methods" (Crampton \& Wagner, 1994, p. 67). They concluded that percept-percept inflation is more the exception than the rule.

In the absence of having multiple sources of data for comparison, it is difficult to assess the presence of bias in a single study. One of the only methods offered is Harman's one-factor test (Harman, 1967; Schriesheim, 1979). According to this approach, if common method variance is a serious problem, it would be expected that a single factor would emerge from a factor analysis or one general factor to account for most of the covariance of the variables (Podsakoff \& Organ, 1986). The principal components factor analysis of all self- 
report items in the survey resulted in a 10-factor solution. Additionally, the analysis indicated that a one-factor model only accounted for $32 \%$ of the variance. While it is not possible to rule out percept-percept bias in the current study, it appears that use of a self-report method for the current study does not pose a significant threat to the validity of the present findings. 


\section{STUDY 2}

Study 2 involved confirmation of the measurement model and tests of the proposed latent variable model. Relationships in the latent variable model are shown in Figure 1 and are specified in Hypotheses 1 through 11. These relationships were tested through a series of nested models using structural equation modeling.

\section{Method}

\section{Participants}

The 609 participants were full-time employees of a medical center located in the mid-Atlantic region of the United States. The center operates as both an educational institution and as a major provider of health services to the community. Those participating in the survey were $9 \%$ executives/administration, $22 \%$ faculty, $22 \%$ professionals/non-faculty and clinicians, $16 \%$ technical/paraprofessionals (e.g., registered nurse, research assistant, manager), $23 \%$ clerical (e.g., receptionist, administrative support, secretarial support), and 8\% maintenance and service personnel (e.g., skilled craft, materials, mailroom). Respondents were $74.6 \%$ White non-Hispanic or Latino, $16.2 \%$ Black or African American, $6.5 \%$ Asian or Pacific Islander, and $2.7 \%$ Other. The average age of the participants was 41.2 years $(S D=10.4$ years), average workgroup size was 9.2 people ( $S D=8.2$ people), average tenure was 6.7 years $(S D=6.6$ ), and $75 \%$ were female. 


\section{Sample Size}

Power analysis is a procedure for estimating sample size required to achieve sufficient statistical power to avoid a Type II error (failing to reject a false null hypothesis). While a number of power analysis techniques exist (Cohen, 1988), few are appropriate for estimating size requirements for structural equation modeling (SEM: MacCullum, Browne \& Sugawara, 1996; Schumacker \& Lomax, 1996). While power analysis, in general, estimates sample size as a function of statistical power and expected effect size, in SEM other concerns exist. For example, larger samples are sometimes needed to maintain accuracy of model fit estimations and to obtain good parameter estimates (MacCullum et al., 1996; Schumacker \& Lomax, 1996). For this reason, general sample size guidelines have been developed for analyses utilizing SEM.

A variety of guidelines have been offered, with some dependent on certain assumptions. Boomsma (1982) and Ding, Velicer, and Harlow (1995) recommended a sample size of 200 as adequate for most SEM. Others recommend a size in relation to the number of parameters. Bentler and Chou (1986) suggested an adequate size could be based on a sample to parameter ratio of 5 to 1 for normally distributed data while Tanaka (1987) recommended a ratio of 4 to 1 . Bentler and Chou (1986) increase the ratio to 10 to 1 for nonnormal data (noting that SEM assumes both normal univariate and multivariate distributions).

MacCullum et al. (1996) developed one of the only analyses for estimating power and associated minimum sample size for SEM. Their procedure is based 
on the Root Mean Square Error of Approximation (RMSEA; Steiger, 1990) which is a SEM indicator of model fit. Through empirical analyses, general guidelines have been offered for evaluating RMSEA values (see MacCallum et al., 1996, for a discussion). Generally, RMSEA values less than 0.05 are considered a good fit, 0.05 to 0.08 are considered a moderate fit, and larger values are considered indicative of a poor fit. According to their approach, the null hypothesis $\left(H_{0}\right)$ is the hypothesized value of the RMSEA (let this value be $e_{0}$.). If $H_{0}$ is false, the actual value of the RMSEA is not $e_{o}$ but value $e_{a}$. The value of $e_{a}$ represents the degree of lack of fit of the specified model in the population. The difference between $e_{o}$ and $e_{a}$ reflects the effect size and identifies the degree to which $H_{0}$ is incorrect (noting that this numerical difference is not the numerical value of the effect size which is affected by the researcher's choice of values for $e_{0}$ and $e_{a}$ ). MacCullum et al. (1996) suggest using a value of $e_{0}<.05$ for $H_{0}$ and a value of $e_{a}$ $<.08$ for the alternative hypothesis. After selecting desired power and alpha levels and determining the degrees of freedom, MacCullum et al. (1996) provide an iterative approach for determining the necessary sample size. Additionally, they provide a table for sample sizes for various degrees of freedom when alpha is .05 and power is .80 (which is the case for the current study).

Review of data collected in Study 1 indicated that most variables had some kurtosis and skewness. Kurtosis varied from moderately platykurtic (e.g., organizational commitment, turnover intentions) to moderately leptokurtic (e.g., workgroup inclusion, peer support). Additionally, most variables showed some 
degree of negative skew. Thus, there are at least minimal levels of violations of the assumption of univariate normality.

Planned analyses of the structural model (see Figure 1) required the estimation of $\mathbf{3 6}$ parameters with 30 degrees of freedom. Based on the table provided by the authors, the MacCullum et al. (1996) power analysis method resulted in a sample size of approximately 314 to 366 . In contrast, the Bentler and Chou (1986) method resulted in a sample size of $300(10 \times 30)$. Based on these estimates the current sample of 609 was considered sufficient to avoid a Type II error.

\section{Measures}

Study 2 utilized the measures developed in Study 1, with the following additions and changes:

Workgroup satisfaction. A four-item measure was created to assess general satisfaction with the immediate workgroup. This measure was constructed by altering the item wording of the measure of organizational satisfaction created in Study 1.

Organizational inclusion and workgroup inclusion. Three items and two items were added to the measures of organizational inclusion and workgroup inclusion, respectively. These items are consistent with content used in Study 1 and were added to lengthen the measures (which will help maintain strong internal consistency reliability). After these additions each scale consisted of eight items. 


\section{Procedure}

Surveys packets were mailed to all 1022 full-time employees working at the medical center. Survey packets were distributed via inter-office mail. (See Appendix A, Table A2 for a copy of the survey packet.) The packets consisted of

a cover letter, the survey, and demographic questions. The cover letter described the nature of the study. The letter included an endorsement of the project by the Dean of the medical center and explained that all responses would remain anonymous and confidential. As an incentive for participation, a donation of $\$ 5$ for each returned survey was pledged to the American Red Cross relief effort for families wounded in New York City by the events of September 11, 2001. One week after the initial mailing a follow-up letter was sent reminding people to complete and return the survey, and included instructions on how to obtain a replacement copy of the survey. A total of 609 usable surveys were returned for a response rate of $60 \%$.

The response rate was further analyzed by demographics. Response rates were $97 \%$ for executives/administration, $55 \%$ for faculty, $67 \%$ for professionals/non-faculty and clinicians, $67 \%$ for technical/paraprofessionals (e.g., registered nurse, research assistant, manager), $45 \%$ for clerical (e.g., receptionist, administrative support, secretarial support), and $76 \%$ for maintenance and service personnel (e.g., skilled craft, materials, mailroom). Response rates were $64 \%$ for females and $49 \%$ for males. 


\section{Analytical strategy}

The following section addresses various decisions related to the analytical procedures. These include selection of fitting algorithms, selection of fit indices, treatment of missing data, procedures for performing an intrascale confirmatory factor analysis, procedures for performing an interscale confirmatory factor analysis, procedures for assessing the latent variable model, and procedures for estimating error. Most analyses were conducted with the use of AMOS software version 4.0 (Arbuckle, 1997).

Fitting algorithm. AMOS makes available for use several fitting algorithms: generalized least squares (GLS), maximum likelihood (ML), and weighted least squares (WLS; Schumacker \& Lomax, 1996). Hypothesis testing for structural equation modeling falls into two broad classes: tests of overall model fit and significance tests of individual parameter estimates. Both classes assume that data being tested have multivariate normal distributions in the population from which the sample data are drawn. If data are multivariate normal and the hypothesized model is the "true" model in the population (not misspecified), ML, GLS and WLS produce similar results. If the sample data are not multivariate normal and the model is misspecified, then it is possible that the overall model fit indices or individual parameter estimates will be biased, and ML, GLS and WLS will produce different results (Olsson, Foss, Troye \& Howell, 2000; Olsson, Troye, \& Howell, 1999).

It is assumed that all models are misspecified to some extent. And, as discussed in Study 1, the initial data collection indicated that the data were not 
univariate normal in distribution. Several studies have compared the accuracy of fit indices and parameter estimates under different conditions. Recent work suggests that under all conditions, ML and GLS are preferable to WLS (Olsson et al., 2000). Overall, ML is most robust to kurtosis and model misspecification compared to GLS or WLS in terms of empirical fit and parameter estimates (Olsson et al., 1999, 2000). ML tends to produce conservative values of fit when models are misspecified and data are non-normal. (Note that ML is the most robust of the three, but fit estimates from ML are still affected by non-normal data.) GLS under performs relative to ML in that GLS accepts incorrect models more often than ML, and GLS returns inaccurate parameter estimates more often than ML (e.g., Olsson et al., 1999). GLS produces fit indices that are too "good" when the model is misspecified and produces biased parameters (Olsson et al., 1999, 2000). WLS actually provides better fit as data becomes more kurtotic, meaning it rewards the researcher for non-normal data.

Olsson et al. (2000) recommend the use of multiple fitting algorithms. If the algorithms provide similar parameter estimates (noting that the focus is on parameter estimates and not estimates of overall model fit), there is an indication that the parameter estimates are accurate. If the algorithms produce different estimates of overall model fit, then one must consider the extent to which the data are not multivariate normal and the level of misspecification. Consistent with this approach, both ML and GLS algorithms were used for the current study.

Fit indices. Three goodness-of-fit indices were used to determine the fit of the models: The Root Mean Square Error of Approximation (RMSEA; Steiger, 
1990), the Tucker-Lewis Index (TLI; Bentler \& Bonett, 1980; Tucker \& Lewis, . 1973), and the Comparative Fit Index (CFI; Bentler \& Bonett, 1980). Note that the TLI is sometimes labeled the Bentler-Bonett Non-Normed Fit Index (NNFI). The latter name reflects the work of Bentler and Bonett (1980) who discussed the Tucker-Lewis coefficient in the context of structural equation modeling. These fit statistics were selected because they are unbiased estimators of the fit between the sample and population covariance matrices (Marsh, Balla, \& McDonald, 1988; Berndt, 1998). Generally, CFI and TLI values greater than .90 and, as already stated, RMSEA values less than .08 are indicative of moderate model fit. CFI and TLI values greater than .95 and RMSEA values less than .05 are indicative of good model fit. However, RMSEA values tend to be influenced by model complexity (i.e., number of latent variables). For simple models (i.e., models with fewer than five latent variables) with two or more indicators per latent variable, Berndt (1998) suggests using a RMSEA value less than .08 as indicative of good fit. This alternative value was used for the intrascale confirmatory factor analyses.

Treatment of missing data. Missing data occur because a participant leaves one or more survey items unanswered. Typical solutions to missing data include listwise and pairwise deletion. These methods involve deletion of part or all of a participant's data. These methods are undesirable for several reasons (Brown, 1994; Little \& Rubin, 1987) including the loss of statistical power (listwise deletion was used in Study 1 since statistical power was not at risk). Mean substitution is another possible solution. However, this results in decreased 
variance, which is also undesirable. Famili, Shen, Weber and Simoudis (1997) recommend that when $\mathbf{2 0 \%}$ of responses are missing for a participant, all data for that participant should be removed. $A$ total of 623 surveys were returned. Applying the $20 \%$ rule, data for 14 participants were removed leaving a net of 609 usable surveys.

When fewer than $20 \%$ of responses are missing, there are ways of estimating responses that are more sophisticated than mean substitution. These procedures take into account all available data points in making the estimates. Such an altemative is the maximum likelihood estimation method (Little, 1993; Little \& Rubin, 1987).

Maximum likelihood estimation is a multiple imputation process that works by generating a maximum likelihood-based covariance matrix and a vector of means (Little, 1993; Little \& Rubin, 1987). The natural variability that occurs among individuals' response patterns is estimated based on data available in the entire data set. Multiple imputation then imputes actual data values to fill in the incomplete data points in the data matrix. The AMOS software has a multiple imputation option to replace missing data. However, this option is only available for the ML fitting algorithm and not the GLS. Therefore, Schafer's (1997) NORM program was used to replace the missing values. This resulted in the estimation of 47 missing values across participants.

Intrascale confirmatory factor analysis. Confirmatory factor analysis (CFA) was used to help support the validity of the measurement model explored in Study 1. Intrascale CFA was used to assess the unidimensionality of each scale. 
CFA is a method for evaluating whether a specified factor model provides a good fit to the data (Floyd \& Widaman, 1995). CFA offers some advantages over other factor analytic techniques, such as not assuming that all common factors are correlated (or uncorrelated) or that all observed variables are directly affected by all common factors, and allowing for correlated measurement error (Long, 1983). With CFA, the researcher specifies the paths between observed and latent variables, thus allowing the researcher to evaluate directly whether a specified factor model provides a good fit to the data (Bollen, 1989; Floyd \& Widaman, 1995). Like exploratory factor analysis, CFA generates factor loadings, which are indices of how well each item measures its associated latent variable. In contrast to exploratory factor analysis, in CFA items are fixed to load on a specific latent variable. CFA then allows the researcher to test the significance of each item loading.

In CFA, factor loadings can be viewed as regression coefficients in the regression of observed variables on latent variables. Thus, the standard factor loadings of observed variables (i.e., individual items in this case) on latent variables (i.e., factors) are estimates of the validity of the factors. The larger the factor loadings the stronger the evidence that the measured variables of a factor represent the underlying construct (Bollen, 1989). For each scale, the hypothesized unidimensionality of the scale was tested against the null hypothesis that the scale was multidimensional. In addition to assessing the unidimensionality of each scale, internal reliability of each scale was also 
reviewed to determine the unassociated variance present in the measure of the latent variable.

Interscale confirmatory factor analysis. In addition to testing the unidimensionality of the scales, the distinctiveness of each scale from the other scales was also of interest. The interscale CFA continues evaluation of the measurement model and, therefore, does not specify any relationships among the latent constructs. Three different measurement models were tested and compared to determine which model fit the data best (Anderson \& Gerbing, 1988; James, Mulaik, \& Brett, 1982). The first model consisted of a single factor with all items loading on that factor. The second consisted of three factors, one representing the antecedents, one representing inclusion, and one representing the consequences (see Figure 1). The third and final model consisted of the 11factor structure implied by the model in Figure 1. Chi-square difference tests and the three fit indices (i.e., TLI, CFI, and RMSEA) were used to determine the extent to which each increasingly complex model fit the data best. For the chisquare difference test, the change to the chi-square statistic resulting from each successive model was tested against the chi-square statistic of the previous model. A significant chi-square difference statistic indicates a significant improvement in the overall fit of the model over the previous model. In addition, the three fit indices were reviewed to assess model fit.

Latent variable model assessment. The structure of the latent variable model specifies the causal effects and relationships among the latent variables. As with the interscale CFA, a nested model approach was used to assess the 
latent variable model (Anderson \& Gerbing, 1988; James et al., 1982). The nested models were intended to assess overall ability of the proposed model to fit the data.

A series of four nested models were compared to evaluate the hypothesized latent variable model (see Figure 1). The nested models created a series of increasingly complex structural relationships. The initial model (the independence model) consisted of no causal pathways among the latent variables. Model 2 specified pathways from the five antecedent variables (employee participation, work life and personal life balance, organizational communication, representation of differences, and peer support) to organizational inclusion and workgroup inclusion (only those pathways shown in Figure 1 were specified). Additionally, the reciprocal relationship between the inclusion variables was specified. Model 3 added relationships between the inclusion variables and three consequence variables (organizational commitment, organizational satisfaction, and workgroup satisfaction) and relationships among these three consequence variables. The final model (the full model) added relationships from organizational commitment and organizational satisfaction to the exogenous variable: Turnover intentions.

As with the interscale CFA, comparison of the indices of fit (i.e., TLI, CFI, and RMSEA) and differences in chi-square values among the nested latent variable models indicated whether the increasing complexity of the models could be justified. In addition to evaluating overall model fit, individual parameter estimates were examined for both statistical significance and for unreasonable 
values (e.g., inappropriate parameter value signs). The squared multiple correlations were examined for each causal relationship in the model. These squared correlations estimate the extent to which the other specified latent variables predict the dependent latent variables. The larger the squared multiple correlations, the stronger the relationships.

Estimating error. Tests of the latent variable model used mean scale scores as the observed variables. To avoid underidentification of the model, it was necessary to fix the scales' Theta-Epsilon values (i.e., measurement error values). Error values were fixed using a standard formula (i.e., $s^{2}$ error $=s^{2} \times(1-$ $\left.r_{x}\right)$ where $s^{2}$ was a scale variance and $r_{x x}$ was a scale composite reliability. Variance and reliability estimates were taken from the CFA.

Results for Study 2

\section{Percept-percept Inflation}

As with Study 1, Harman's one-factor test for common method variance was used (Harman, 1967; Schriesheim, 1979). A principal components factor analysis indicated that a one-factor model only accounted for $35 \%$ of the total variance, with an 11 -factor solution accounting for $75 \%$ of the total variance. As with Study 1, these results provide some assurance that common method variance was not a serious threat to validity of the findings (Podsakoff \& Organ, 1986).

\section{Data distribution}

As discussed above, data that are not multivariate normal and models that are misspecified can distort both the indices of overall model fit and parameter 
estimates. Review of the data indicated univariate skewing and kurtosis were present in many of the variables. In the extreme case, there was significant range restriction. Several variables were significantly skewed (Workgroup Inclusion = -1.80, Workgroup Satisfaction $=-1.69$, Peer Support $=-1.27$, Organizational Satisfaction $=-1.00$, and Employee Participation $=-.95$ ) and kurtosies were around $+/-1.00$. When data are not univariate normal, multivariate normality is not possible (Bollen, 1989). Amos provides Mardia's coefficient for estimate of standardized multivariate kurtosis (Bollen, 1989). The test statistic for no multivariate kurtosis approximates a chi-square distribution. The statistic was significant, indicating multivariate kurtosis (Romeu \& Ozturk, 1993). Statistical analyses must be reviewed in consideration that the data were not multivariate normal, as discussed in the Method section.

Intrascale Confirmatory Factor Analysis

Results of intrascale confirmatory factor analyses (CFA) using the ML and GLS fitting algorithms are shown in Appendix B and summarized in Table 4. Table 4 provides the fit indices and Appendix B provides individual item information (standardized factor loadings, measurement error variances, and item reliability estimates) along with chi-square estimates and composite reliability estimates. These indicators along with standardized residuals were reviewed to assess individual scale items and overall scale performance. 
Table 4

Summary of Maximum Likelihood and Generalized Least Squares Confirmatory Factor Analyses

\begin{tabular}{lccc|ccc}
\hline \multirow{2}{*}{ Scale } & \multicolumn{4}{c}{ Maximum Likelihood } & \multicolumn{3}{c}{ Generalized Least Squares } \\
\cline { 2 - 7 } & TLI & CFI & RMSEA & TLI & CFI & RMSEA \\
\hline $\begin{array}{l}\text { Workgroup } \\
\text { Inclusion }\end{array}$ & .93 & .95 & .15 & .43 & .59 & .13 \\
$\begin{array}{l}\text { Organizational } \\
\text { Inclusion }\end{array}$ & .90 & .93 & .16 & .39 & .56 & .13 \\
$\begin{array}{l}\text { Employee } \\
\text { Participation }\end{array}$ & .94 & .96 & .15 & .54 & .73 & .14 \\
$\begin{array}{l}\text { Peer Support } \\
\text { Organizational }\end{array}$ & .88 & .93 & .20 & .42 & .65 & .16 \\
$\begin{array}{l}\text { Communication } \\
\text { Work-life Balance }\end{array}$ & .88 & .93 & .20 & .42 & .65 & .16 \\
$\begin{array}{l}\text { Representation of } \\
\text { Differences }\end{array}$ & .74 & .84 & .22 & .41 & .64 & .16 \\
$\begin{array}{l}\text { Organizational } \\
\text { Commitment }\end{array}$ & .95 & .86 & .20 & .35 & .61 & .17 \\
$\begin{array}{l}\text { Organizational } \\
\text { Satisfaction }\end{array}$ & 1.00 & 1.00 & .00 & 1.00 & 1.00 & .00 \\
$\begin{array}{l}\text { Workgroup } \\
\text { Satisfaction }\end{array}$ & 1.00 & 1.00 & .01 & 1.00 & 1.00 & .01 \\
$\begin{array}{l}\text { Turnover } \\
\text { Intentions* }\end{array}$ & & & & & & .12 \\
\hline
\end{tabular}

Note. $\mathrm{TLI}=$ Tucker-Lewis index; $\mathrm{CFI}=$ comparative fit index; $\mathrm{RMSEA}=$ root mean square error of approximation. "Because of insufficient degrees of freedom, final goodness of fit indices could not be calculated.

Reviewing Table 4 and Appendix B, it is clear that ML and GLS resulted in different fit indices and, to a lesser degree, parameter estimates. Generally, parameter estimates for the GLS and ML fitting algorithms were very similar, with GLS factor loadings slightly higher than ML for most scales; this provides evidence that the parameter estimates were stable (Olsson et al., 2000). However, goodness of fit indices for both the ML and GLS procedures indicated poor fit for most scales with few exceptions (e.g., organizational satisfaction). 
Although many of the overall scale fit indices indicated poor fit, indicators on the item level were satisfactory (e.g., all factor loadings were significant), with most factor loadings in the .80 and .90 range. However, there were some exceptions. Four items had loadings below .60 (.44 was the lowest) and several items had high standardized residuals (i.e., > .10). Most of these items are part of the four scales with the lowest fit indices (i.e., Peer Support, Organizational Communication, Work-life Balance, and Representation of Differences). Interscale Confirmatory Factor Analysis

Evaluation of the measurement model continues by testing the distinctiveness of each scale from the other scales. As already described, a series of three increasingly complex measurement models were tested and compared to determine which model fit the data best (Anderson \& Gerbing, 1988; James et al., 1982). The first model consisted of a single factor, the second consisted of three factors, one representing the antecedents, one representing inclusion, and one representing the consequences (see Figure 1), and the third consisted of the 11-factor structure implied by in Figure 1. Results of the chisquare difference tests and the goodness-of-fit indices for maximum likelihood and generalized least squares are shown in Tables 5 and 6, respectively. 
Table 5

Measurement Model Comparisons - Maximum Likelihood

\begin{tabular}{lccccccc}
\hline \multicolumn{1}{c}{ Model } & df & Chi-Square & TLI & CFI & RMSEA & $\Delta d f$ & $\begin{array}{c}\Delta \text { Squi- } \\
\text { Square }\end{array}$ \\
\hline 1 Factor Model & 1890 & $23210.45^{*}$ & .38 & .40 & .14 & - & - \\
3 Factor Model & 1887 & $20150.23^{*}$ & .47 & .49 & .13 & 3 & $3060.22^{*}$ \\
11 Factor Model & 1835 & $5467.60^{*}$ & .90 & .90 & .05 & 52 & $14682.63^{*}$ \\
\hline
\end{tabular}

Note. ${ }^{*} p<.05 . d f=$ degrees of freedom; $\Delta d f=$ change in degrees of freedom; $\Delta$ Chi-Square = change in chi-square; $T L I=$ Tucker-Lewis index; $\mathrm{CFI}=$ comparative fit index; RMSEA = root mean square error of approximation.

Table 6

Measurement Model Comparisons - Generalized Least Squares

\begin{tabular}{lccccccc}
\hline \multicolumn{1}{c}{ Model } & df & Chi-Square & TLI & CFI & RMSEA & $\Delta d f$ & $\begin{array}{c}\Delta \text { Chi- } \\
\text { Square }\end{array}$ \\
\hline 1 Factor Model & 1890 & $5099.16^{*}$ & .04 & .07 & .05 & - & - \\
3 Factor Model & 1887 & $4726.90^{*}$ & .15 & .18 & .05 & 3 & $372.26^{*}$ \\
11 Factor Model & 1835 & $3534.99^{*}$ & .48 & .51 & .04 & 52 & $1191.91^{*}$ \\
\hline
\end{tabular}

Note. $*<<.05 . d f=$ degrees of freedom; $\Delta d f=$ change in degrees of freedom; $\Delta$ Chi-Square = change in chi-square; $T L I=$ Tucker-Lewis index; $C F I=$ comparative fit index; RMSEA = root mean square error of approximation.

Comparisons of the indices of fit and differences in chi-square values (Tables 5 and 6 ) indicated that the increasing complexity of the models could be justified; the implied measurement model (see Figure 1) fit the data better than the two comparison models. However, ML and GLS fit indices indicated a poor fit for the proposed 11-factor model.

The poor fit is in part a reflection of individual scale items identified through the intrascale CFA. To help further understanding of the poor fit for the 11-factor model, exploratory factor analysis was performed. This revealed 
greater cross loadings than was found in the sample analyzed in Study 1. For example, items on the organizational satisfaction scale and organizational commitment scale had higher cross loadings in Study 2 . This may indicate that the sample from Company $X$ could not discriminate between some of the constructs. Alternatively, it may that the rules applied to the exploratory factor analysis in Study 1 (i.e., a good item was defined as having a loading on the intended component of .50 or greater and on a different component of less than .35) were too lenient. Regardless of the reason, the result is some level of misspecification of the measurement model.

Descriptive Statistics

Table 7 summarizes the descriptive statistics, including scale means, standard deviations, composite reliability estimates, and correlations among the scales. 


\section{Table 7}

Means, Standard Deviations, and Correlations for Study 2

\begin{tabular}{llllllllllllll} 
Variable & $M$ & $S D$ & 1 & 2 & 3 & 4 & 5 & 6 & 7 & 8 & 9 & 10 & 11 \\
\hline
\end{tabular}

1. Workgroup Inclusion $\quad 4.410 .87(.84)$

2. Organizational Inclusion $3.561 .03 \quad .36$ (.71)

3. Employee Participation $3.851 .14 \quad .52 \quad .34$ (.69)

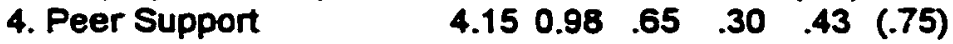

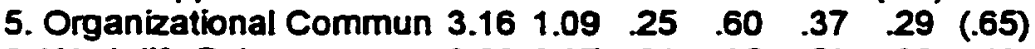

$\begin{array}{llllllllll}6 . & \text { Work-life Balance } & 3.66 & 0.97 & .31 & .35 & .53 & .30 & .43 & (.58)\end{array}$

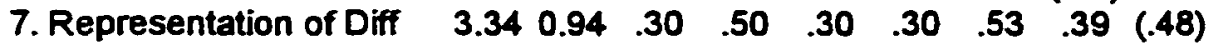

$\begin{array}{lllllllllll}\text { 8. Organizational Comit } & 3.32 & 1.10 & .35 & .69 & .37 & .32 & .47 & .33 & .41 & (.68)\end{array}$

$\begin{array}{llllllllllll}\text { 9. Organizational Sat } & 3.91 & 1.01 & .31 & .63 & .41 & .28 & .54 & .48 & .44 & .72 & (.78)\end{array}$

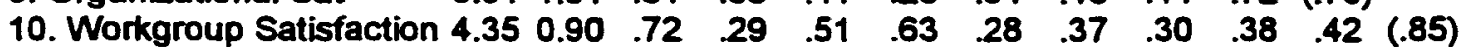

$\begin{array}{lllllllllllllll}\text { 11. Tumover Intentions } & 2.37 & 1.38 & -.34 & -.42 & -.36 & -.23 & -.40 & -.37 & -.32 & -.51 & -.53 & -.41 & (.74)\end{array}$

Note: All rs $>.10, p<.05 . n=609$. Figures in parentheses are composite reliability estimates.

\section{Latent Variable Model Assessment}

As already described, a series of four nested models were tested and compared to determine which model fit the data best (Anderson \& Gerbing, 1988; James et al., 1982). The first or independence model specified no causal pathways among the latent variables, model 2 specified pathways from the five antecedent variables (see Figure 1) to organizational inclusion and workgroup inclusion and added the reciprocal relationship between the inclusion variables, model 3 added pathways from the inclusion variables to the consequence variables (organizational commitment, organizational satisfaction, and workgroup satisfaction) and added the relationship from organizational satisfaction to organizational commitment, and model 4 or the full model added pathways to turnover intentions. Results of the chi-square difference tests and the goodness- 
of-fit indices for maximum likelihood and generalized least squares are shown in

Tables 8 and 9, respectively.

Table 8

Nested Model Comparisons - Maximum Likelihood

\begin{tabular}{lccccccc}
\hline \multicolumn{1}{c}{ Model } & \multicolumn{9}{c}{$\begin{array}{c}\text { Chi- } \\
\text { Mol }\end{array}$} & Square & TLI & CFI & RMSEA & $\Delta d f$ & $\begin{array}{c}\Delta \text { Chi- } \\
\text { Square }\end{array}$ \\
\hline Model (Indep) & 55 & $3385.64^{*}$ & .00 & .00 & .32 & - & - \\
Model 2 & 38 & $1952.29^{*}$ & .17 & .43 & .29 & 17 & $1433.35^{\star}$ \\
Model 3 & 34 & $595.27^{*}$ & .73 & .83 & .17 & 4 & $1357.02^{\star}$ \\
Model 4 (Full) & 32 & $364.19^{*}$ & .83 & .90 & .13 & 2 & $231.08^{*}$ \\
\hline
\end{tabular}

Note. $p<.05 . d f=$ degrees of freedom; $\Delta d f=$ change in degrees of freedom; $\triangle$ Chi-Square = change in chi-square; $T L I=$ Tucker-Lewis index; $C F I=$ comparative fit index; RMSEA = root mean square error of approximation; Indep = independence model.

Table 9

Nested Model Comparisons - Generalized Least Squares

\begin{tabular}{lccccccc}
\hline \multicolumn{1}{c}{ Model } & $d f$ & $\begin{array}{c}\text { Chi- } \\
\text { Square }\end{array}$ & TLI & CFI & RMSEA & $\Delta d f$ & $\begin{array}{c}\Delta \text { Chi- } \\
\text { Square }\end{array}$ \\
\hline Model 1 (Indep) & 55 & $716.73^{*}$ & .00 & .00 & .14 & - & - \\
Model 2 & 38 & $540.83^{*}$ & .10 & .24 & .15 & 17 & $175.90^{*}$ \\
Model 3 & 34 & $325.97^{\star}$ & .29 & .56 & .12 & 6 & $214.86^{*}$ \\
Model 4 (Full) & 32 & $252.01^{*}$ & .43 & .67 & .11 & 2 & $73.96^{*}$ \\
\hline
\end{tabular}

Note. ${ }^{*}<.05 . d f=$ degrees of freedom; $\Delta d f=$ change in degrees of freedom; $\Delta$ Chi-Square $=$ change in chi-square; $\mathrm{TLI}=$ Tucker-Lewis index; $\mathrm{CFI}=$ comparative fit index; RMSEA = root mean square error of approximation; Indep $=$ independence model.

The structural model addresses how well the proposed relationships among the latent variables fit the covariance matrix obtained from the sample. Comparisons of the indices of fit and differences in chi-square values (Tables 8 
and 9) indicated that the increasing complexity of the models was justified. The proposed model (see Figure 1) fit the data better than the three comparison models. The standardized parameter estimates of the paths in the model are shown in Figure 2 and 3. The path parameter estimates for ML and GLS algorithms were similar, suggesting the stability of the parameter estimates and, more importantly, indicating that the parameter estimates were accurate (Olsson et al., 2000). However, three of the 13 proposed paths were not significant (i.e., employee participation and work life/personal life balance to organizational inclusion, and workgroup inclusion to organizational inclusion). The individual paths are addressed in the Study 2 discussion section. 


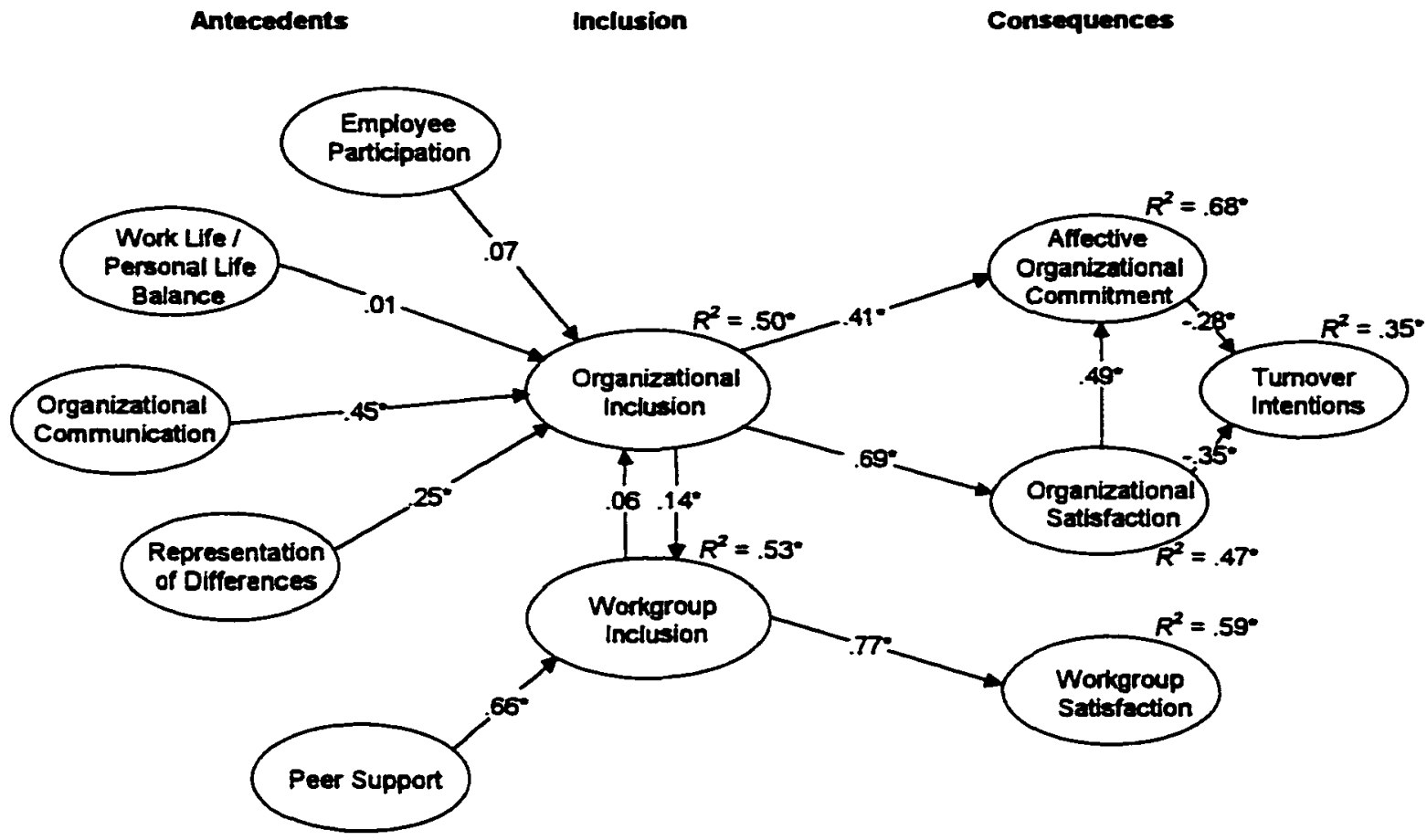

Figure 2. Structural equation model of the relationships of organizational and workgroup inclusion with antecedent and consequence variables. Method = Maximum Likelihood. Standardized path parameters and squared multiple correlations are shown: $" p<.05$. 


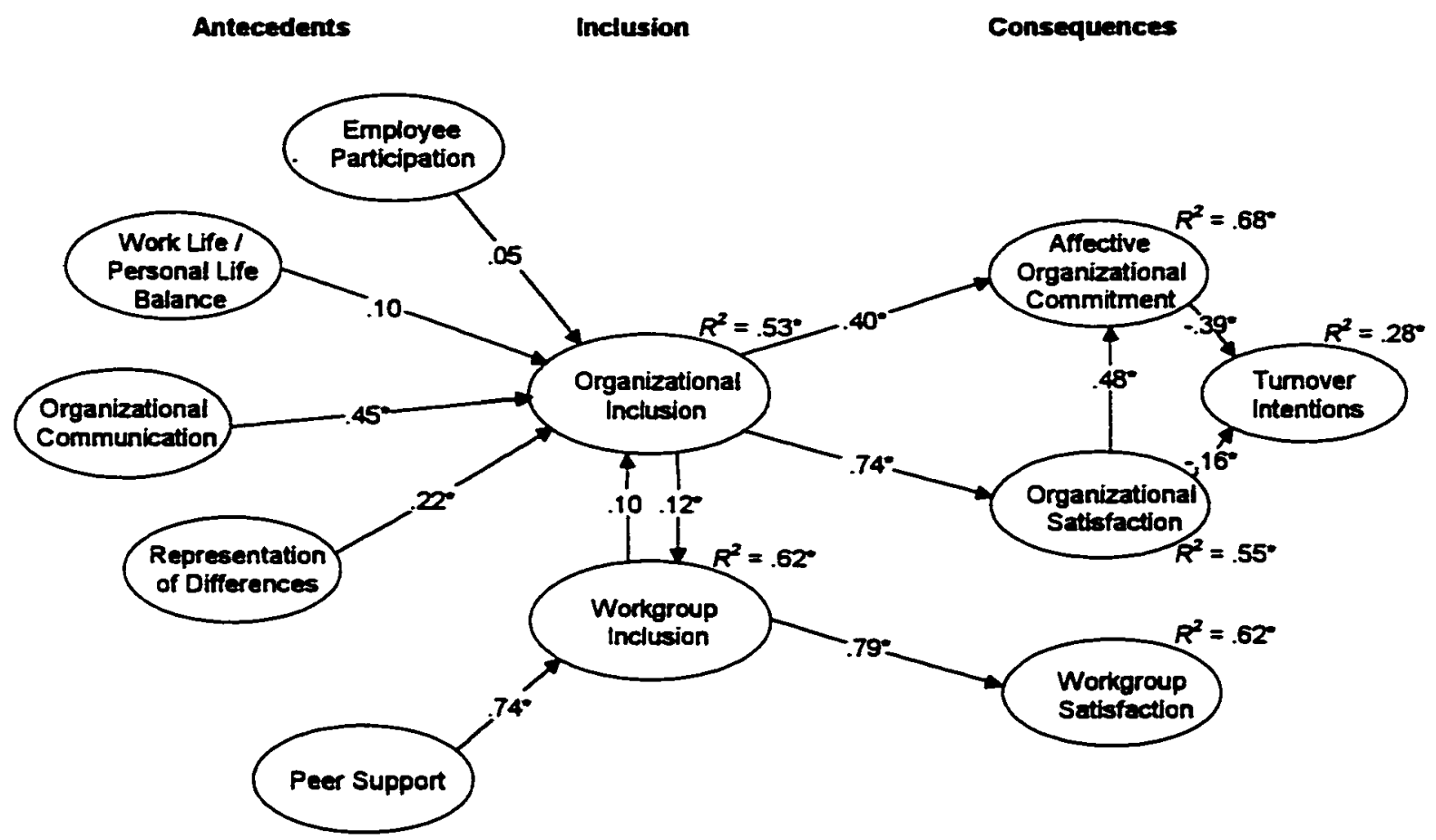

Figure 3. Structural equation model of the relationships of organizational and workgroup inclusion with antecedent and consequence variables. Method = Generalized Least Squares. Standardized path parameters and squared multiple correlations are shown: " $p<.05$.

The squared multiple correlation $\left(R^{2}\right)$ was examined for each causal relationship in the model (see Figure 2 and 3). These squared correlations estimate the extent to which the other specified latent variables predict the dependent latent variables. The larger the squared multiple correlation, the stronger the relationship. (Note that $R^{2}$ values are not indicative of model fit.)

For nonrecursive models (i.e., those with feedback loops or reciprocal causation), traditional linear $R^{2}$ are not accurate estimates of variance in the dependent variables explained by the predictor variables (Bentler \& Raykov, 
2000). This is because a predictor (e.g., organizational inclusion predicting organizational commitment) can be a predictor to other variables explaining variance in the dependent variable (e.g., organizational inclusion to organizational satisfaction to organizational commitment). Bentler and Raykov (2000) provide procedures for calculating variance explained in latent dependent variables for nonrecursive models. EQS 6 software (Bentler, 1995) provides estimates using this procedure and the software was used to calculate the squared correlations shown in Figures 2 and 3. Each squared correlation was significant and accounted for .28 to .68 of the variance in the dependent variables.

The chi-square comparisons, the individual path parameter estimates, and the squared multiple correlations were acceptable for the most part. However, the goodness of fit indices (i.e., TLI, CFI, and RMSEA) indicated a poor fit of the overall structural model; the overall conclusion is that the model is misspecified. Alternatively, there may be no misspecification but the fit indices may be a reflection of poor construct measurement, or there may be both poor measurement and model misspecification. Regardless of the cause, any conclusions regarding individual parameter estimates must be qualified because of the poor overall fit.

ML and GLS resulted in considerably different values for the indices of overall fit. These differences are discussed in the next section.

Differences in fit indices. For both the measurement model and the latent variable model, GLS indices were significantly poorer than those generated by 
ML (see Tables 5, 6, 7, and 8 for differences). However, the cause for this is actually poorer detection of misspecification by GLS. As pointed out by Olsson et al. $(1999,2000)$, this is usually the case, especially when there is model misspecification combined with data that are not multivariate normal, as was the case with the current study. The TLI and CFI are part of a class of indices called incremental fit indices. In general, these indices compare the fit of the specified model to the null or independence model. The formula for these indices usually utilizes the chi-square for the specified model in the numerator of the equation and the chi-square for the null or independence model in the denominator. And, the smaller the denominator relative to the numerator, the poorer the fit index.

As an example, consider the CFI for model 4 in assessment of the latent variable structure (Table 8 and 9). It would appear that GLS indicated a poorer fit than ML. However, this is only because GLS did a poor job of assessing the misspecification in model 1, the independence model. Notice that GLS independence chi-square is not nearly as poor relative to the model 4 chi-square (719.73 versus 252.01). But, in the ML formula the independence chi-square is significantly larger (indicating a very poor fit) relative to the model chi-square (3385.64 versus 364.19). GLS did not detect misspecification as well, especially in the independence model where misspecification is the most severe. As a result, the proposed model does not appear to fit the data well when compared to the independence model. However, the ML was better at detecting a poor fit in the independence model. For any given model in the current study, the GLS model chi-square is smaller than ML (indicating a better fit), yet the fit indices are 
worse for GLS because of how the formulas work. This finding is consistent with recent empirical work (e.g., Olsson et al., 1999, 2000). Note that this explanation applied to the current data only. This explanation may or may not apply to other data or models.

\section{Discussion of Study 2}

Overall, results for both the measurement and latent variable model assessment provided limited support for the proposed structure. Results of the CFAs identified potential misspecification of the measurement model. For the latent variable model, results on the individual parameter level support the majority of the proposed paths. Most path coefficients were significant and both fitting algorithms provided similar parameter estimates indicating that these estimates were stable (Olsson et. al., 2000). However, results indicated that the overall proposed model received poor support. It is important to remember that because the fit of the overall model was poor, specific path results must be viewed with caution and are presented solely as a basis for future research. Individual paths that were significant require replication with a correctly specified model and a valid measurement model before supportive conclusions can be reached. Results for each of the hypothesized paths are described below, followed by a discussion of the overall model fit.

Hypothesized Paths

Hypothesis 1. The exploratory factor analysis and CFAs together provide some support for validity of the inclusion construct and the existence of inclusion for two different referents. In contrast, results did not provide support for a 
significant reciprocal relationship between inclusion variables. The downward influence from organizational inclusion to workgroup inclusion was significant, however, the reciprocal upward influence was not.

It has been suggested that behavior of and attitudes towards individual organizational members are attributed to the organization as a whole because these individuals are acting as representatives of the organization (Levinson, 1965; Wayne et al., 1997). Wayne et al. (1997) found that the relationship an individual develops with his or her supervisor has an influence on the relationship that individual develops with the personified organization. It may be that attitudes towards workgroups do not have the same upward influence that attitudes towards supervisors have. While the supervisor is perceived as acting on the part of the organization in an authority role, peers in workgroups are not in such a hierarchical position and their behavior may be attributed less to the organization.

An alternative explanation may be found in the structure of Company $X$. The organization is divided into fairly autonomous divisions, or schools, such as internal medicine and social sciences. Each division is run fairly independently and has an identifiable leadership. Further, there are few operational interdependencies across many of the subdivisions. Companies in a traditional hierarchical structure are similarly divided into departments and workgroups, and may have significant autonomy. However, such divisions are usually functional and significant interdependencies exist. As a result of the subdivision and lower interdependence in Company $X_{z}$ the personified organization may be perceptually more distal to individuals than in traditional hierarchical structures 
(Lewin, 1943). Simply specifying a path from workgroup inclusion to organizational inclusion omits intermediate inclusion perceptions to the school, department, or area of specialization. However, this same argument is against a downward influence (from organization to workgroup) which was actually supported, noting that the influence was small (beta $=.12$ for GLS and .14 for ML). Future research on inclusion should ensure that the inclusion referents are relevant to the company(s) being studied.

Hypotheses 2 and 3. Results from the present study did support the expected positive relationship from representation of differences and organizational communication to organizational inclusion. Findings support theory asserting that perceived diversity in leadership builds organizational inclusion by demonstrating that individual differences are welcomed and valued by the organization (Ely, 1994; Hayes et al., 2002; Miller, 1998). Findings are also consistent with theory asserting that communications from organizational members are used by employees to form opinions about their relationship with the organization (Salancik \& Pfeffer, 1978) and empirical evidence indicating that communications influence employees sense of membership in the organization (Allen, 1992; Cheney, 1983; Mathieu \& Zajac, 1990; Putti et al., 1990). When employees feel well informed by senior leadership they feel more included in the organization.

Hypotheses 4 and 6. Results from the present study did not support the expected positive relationship from employee participation and work life and personal life balance to organizational inclusion. This finding suggests having 
influence over decisions affecting one's job and support with balancing demands has no affect on perceptions of inclusion, indicating that these factors are unnecessary for creating an inclusive organization. This conclusion is in contrast with theoretical arguments.

Participation in decisions that impact one's work has been considered by many to be an essential element to building inclusive organizations (e.g., Miller, 1998; Miller \& Katz, 1995; Prasad, 2001). Similarly, providing support with work life and personal life balance is believed to provide both instrumental and psychosocial benefits (Adams, 1996; Beehr \& McGrath, 1992; Goldsmith, 1992; House, 1981; Mclntosh, 1991), creating perceptions of caring for one's well-being and concern for the whole person. Empirical evidence shows that support with work life and personal life balance (Grover \& Crooker, 1995; Guzzo at al., 1994; Thompson et al., 1999; Wentling \& Palma-Rivas, 1997) and participation (Brown, 1996; Hutchison \& Garstka, 1996) demonstrate concern for the individual and help build strong attachments.

It may be that theoretical arguments are incorrect and that participation and balance support do not impact the inclusion construct. As an alternative explanation, the non-significant finding may have to do with misspecification of the paths. Both consequences were specified to influence organizational inclusion and not workgroup inclusion. Participation in decision-making and support with work life and personal life balance at least partially involve behavior that occurs within the workgroup. Item content of the scales (see Table A2) explicitly refer to interactions with the 'immediate supervisor.' Participation may 
be an organizational policy, but in practice it usually involves interaction between supervisor and subordinate. The influence was hypothesized to be on organizational inclusion because of the assertion that behavior of organizational members carried out on the part of the organization are considered indicative of the organization and not the individual (Levinson, 1965). It is possible that this assertion does not apply to the current model and that influence of both antecedents is on workgroup inclusion. Future research should consider this possibility.

Hypothesis 5 and 9. Results from the present study did support the expected positive relationships from perceived social support from the immediate workgroup to workgroup inclusion and workgroup inclusion to workgroup satisfaction. This finding supports assertions that environmental features provide experiences that satisfy important individual needs, and fulfillment of those needs creates satisfaction (Likert, 1967; McGregor, 1960; Miller \& Monge, 1986; Ritchie \& Miles, 1970). The finding is also consistent with evidence showing that peers provide significant psychosocial support (Kram \& Isabella, 1985), helping satisfy the need for belonging that is central to inclusion.

Hypotheses 7, 8, and 11. Results from the present study did support the expected positive relationship from organizational inclusion to both organizational commitment and organizational satisfaction. This is consistent with theories that assert that an individual's organizational satisfaction and commitment reflects the extent to which the organization is able to satisfy important needs (Likert, 1967; McGregor, 1960; Miller \& Monge, 1986; Ritchie \& Miles, 1970). As already noted, 
satisfaction of needs is considered the basis for building strong affective attachments to the organization (Meyer et al., 1993; Mowday et al., 1982). Additionally, the results support the expected positive relationship from organizational satisfaction to organizational commitment, which is consistent with existing empirical evidence (e.g., Hayes, 1997; Tett \& Meyer, 1993).

Hypotheses 10. Results from the present study did support the expected negative relationship from organizational commitment and organizational satisfaction to turnover intentions. A substantial quantity of research indicates that organizational commitment and satisfaction mediate the relationship between other factors and turnover intentions (Clegg, 1983; Hayes, 1997; Lance, 1991; Tett \& Meyer, 1993). As shown in Figures 2 and 3, these variables only accounted for .28 and .35 percent of the variance in tumover intentions for GLS and ML, respectively. The remaining variance unaccounted for reflects the many variables that influence turnover cognitions (Mobley et al., 1979). For example, review of written comments from 154 participants indicated that many employees were looking for new jobs because the pay levels at Company $X$ were below market. Pay satisfaction is a potential omitted variable in the current model. Overall Model Fit

The present study provided tentative support for several of the proposed relationships. However, given the poor fit of the overall model, these results should be viewed with caution. There are several explanations for the poor overall model fit. It is possible that the model is simply a poor explanation of the data; the model is misspecified and inclusion has a minimal role in understanding 
attitudes in the context of work. However, the number of significant path coefficients indicates that parts of the model are likely correctly specified.

One potentially significant influence on the overall model fit is the implied assumption that all relationships between the antecedent variables and consequence variables are fully mediated by inclusion. Existing empirical evidence supports direct relationships between many of the antecedent and consequence variables (e.g., participation to satisfaction). It is not uncommon for mediation relationships to be partial. For example, Eisenberger, Armeli, Rexwinkel, Lynch, and Rhoades (2001) proposed a model specifying full mediation of the relationship between perceived organizational support and outcomes such as organizational commitment. Analyses indicated that the proposed mediator, felt obligation, only provided partial mediation of the relationship.

Several procedures exist for testing full and partial mediation using structural equation modeling (e.g., Kenny, Kashy, \& Bolger, 1998). Such procedures are useful for simple models limited to a few variables. However, such procedures are not practical for complex models with several antecedent and outcome variables, like the current one. Omitted paths from partial mediation may make a significant contribution to model misspecification. Future research should consider testing models involving fewer variables.

Another explanation for the overall poor fit is not model misspecification, but poor construct measurement. Results of the CFAs clearly indicated that the measurement was not a good fit to the data. A poor measurement model will 
influence fit of the structural model. It is also possible that the poor fit is a reflection of both poor measurement and misspecification. 


\section{GENERAL DISCUSION}

The concept of organizational inclusion is receiving increasing attention by both scientists (e.g., Davidson \& Ferdman, 2002) and practitioners (e.g., Gilbert \& Ivancevich, 2000). Inclusion has been touted as a new, more effective approach to diversity management (Miller, 1998; Miller \& Katz, 1995; Thomas, 1990), changing the focus from individual differences to an environment that makes all feel welcome. This growing body of literature is almost exclusively theoretical and the concept of inclusion has not been clearly defined. The purposes of the current studies were to clarify the meaning of inclusion in the organizational context and to empirically evaluate the construct.

Overall results from the present studies provided some support for validity of the inclusion construct. Further, results provided some support for inclusion to two different organizational referents: the workgroup and the organization as a whole. Conceptualizing inclusion as a psychosocial need is consistent with a growing body of research on the role of needs in understanding behavior and attitudes. Work by Sheldon, Elliot, Kim, and Kasser (2001) indicated that belongingness or relatedness needs are among the most fundamental for understanding the human experience. It is possible that such needs are learned in early childhood or are the result of evolutionary pressures (Baumeister \& Leary, 1995; McClelland, 1985). The current study indicates that need constructs may be equally valid in the organizational context.

While the current study provided some support for the construct, the related nomological net received poor support. Although results suggest that 
individuals can distinguish between perceptions of inclusion from other attitudes such as satisfaction, the role of inclusion received poor support. Theorists have proposed that environmental features and practices such as participation do not directly influence outcomes. Rather, such factors work to satisfy important needs, which, in turn, increase attachment and satisfaction through the norm of reciprocity (Brown, 1996; Gouldner, 1960; Likert, 1967; McGregor, 1960; Miller \& Monge, 1986; Ritchie \& Miles, 1970, p. 348). Results of this study did not support inclusion as a mediator between environmental features and important outcomes. It may be that the inclusion construct is valid in the context of work, but that its ability to explain attitudes and behavior or mediate relationships is minimal.

Is inclusion a good approach to diversity? It may not have some of the success at getting minorities and women into higher levels of the workplace that affirmative action programs have had (Kravitz et. al., 1996). Further, it does not focus on changing individuals' attitudes and behavior through personal experiences such as formal diversity training programs (Wentling \& Palma-Rivas, 1997). What an inclusive approach does do is change the focus from individual differences and an individual level of change to an environmental level of change. In this approach, focusing on organizational and workgroup level features are used to influence individuals' attitudes and behavior. It had been argued that if these features can satisfy important needs of all, the result will be increased satisfaction with the organization and increased retention, eventually leading to increased diversity of people in higher levels of the workplace. 
However, results of the current study did not provide support for the efficacy of an inclusive approach to managing organizations.

\section{Limitation and Implications}

Because the overall fit of the model was poor and the findings were based on assessment within a specific company, implications of the present study are limited and the tentative findings discussed above should only be used to guide future research. In this section, additional limitations of the present study are presented along with implications for researchers and practitioners working in this area.

One limitation of the study results from timing. Within weeks prior to survey distribution, the Dean of the medical center announced that the organization was in significant financial trouble, that two of the top leaders were having their employment terminated, and that employees should expect future reductions in staff. These announcements were unexpected by the majority of employees and the impact on results of this study are unclear. When possible, future research should attempt to control for the impact of such widely implicating actions by carefully selecting the timing of assessment(s).

A second limitation is representativeness of the sample. Survey methodology included an incentive for participation, a statement of support from the Dean, and a follow-up reminder notice. However, $40 \%$ of the employees chose not to return surveys. While it is unknown if responses were representative of the entire population of the organization, some statistics were available. While $64 \%$ of females chose to participate, only $49 \%$ of males responded. The survey 
was distributed through the Office for Women's Affairs, which was indicated on the letterhead of the cover letter. The Assistant Dean and the Director of Women's Affairs signed the letter. Males may have perceived that the survey was less applicable to them.

There were differences in response rates by position. Almost all of senior leadership and many of the maintenance workers participated, but just over onehalf of faculty responded. Because of the Dean's expressed support, higher response rates for his direct reports were expected. The reason for a low response rate by faculty is unclear. Company $X$ had not conducted a company wide survey in recent years and there was no advance announcement of the current survey. Review of written comments from 154 participants indicated that many employees did not trust leadership (i.e., they were not willing to voice concerns, leadership does not listen) and that many have cognitively withdrawn from the organization over recent months, especially since recent organizational announcements regarding future layoffs. These factors may have negatively affected response rates.

A third limitation was the threat of percept-percept inflation (artificial elevation of bivariate relationships resulting from the use of self-report data as the sole data source). While procedures were taken to identify any possibility of percept-percept bias, it is impossible to detect without multi-source data. As a result, a threat to validity can not be ruled out definitively (Campbell, 1982; Crampton \& Wagner, 1994). Future research is needed that includes data generated from multiple sources (e.g., supervisor-subordinate dyads). 
A fourth limitation of the current study is that it focused exclusively on inclusion from the perspective of managing an organization's human capital. While this perspective is central to building an inclusive organization, it is only part of the total strategy. From a systems perspective, the inclusive organization is involved in its surrounding community and works across organizations. The inclusive organization works to build an external environment that creates access and opportunities to all, especially the disadvantaged who are likely to feel excluded by society as a whole. From an organizational performance perspective, inclusion means building and using diversity of its workforce. Their diverse skills and knowledge can be leveraged to enter new markets or access new talent. For example, having bi-lingual customer service operators or targeting previously overlooked markets. A comprehensive inclusion strategy is one embedded in the goals and objectives of all areas of the organization from human resources, to marketing, to public relations. 


\section{CONCLUSION}

For researchers and practitioners in the area of diversity management and inclusion, the findings from this study are limited. Results do suggest that the construct of inclusion has some level of validity in the context of work and that the construct is related to some antecedent and consequence variables, suggesting that certain organizational features may lead to inclusion. However, the poor overall fit of the proposed model makes any conclusions tentative. The current study provided little support for aspects of an inclusive organization argued by a number of theorists. Unfortunately, the present study does little to provide well supported guidance to the practitioner on how to manage inclusion and does not provide clear support for an inclusive approach in general. Further research is required to assess the efficacy of using an inclusive approach to managing organizations. 


\section{REFERENCES}

Adams, G. A., King, L. A., \& King, D. W. (1996). Relationship of job and family involvement, family social support, and work-family conflict with job and life satisfaction. Journal of Applied Psychology, 81, 411-420.

Allen, M. W. (1992). Communication and organizational commitment: Perceived organizational support as a mediating factor. Communication Quarterly, 40, 357-367.

Allen, N. J., \& Meyer, J. P. (1990). The measurement and antecedents of affective, continuance and normative commitment to the organization. Journal of Occupational Psychology, 63, 1-18.

Anderson, J. C., \& Gerbing, D. W. (1988). Structural equation modeling in practice: A review and recommended two-step approach. Psychological Bulletin, $103,411-423$.

Angle, H. I., \& Perry, J. L. (1983). Organizational commitment: Individual and organizational influences. Work and Occupations, 10, 123-146.

Arbuckle, J. L. (1997). AMOS users' guide version 3.6. Chicago: Smallwaters.

Armeli, S., Eisenberger, R., Fasolo, P., \& Lynch, P. (1998). Perceived organizational support and police performance: The moderating influence of socioemotional needs. Journal of Applied Psychology, 83, 288-297.

Armitage, M. A. (1993). Managing cultural diversity globally and domestically: A federal model for examining programs and competencies for 
leader effectiveness. Paper presented at the Eighth Annual Conference of the Society of Industrial and Organizational Psychology, San Francisco.

Batson, C. D., \& Oleson, K. C. (1991). Current status of the empathyaltruism hypothesis. In M. S. Clark (Ed.), Prosocial behavior (pp. 62-85). Newbury Park: SAGE.

Baumeister, R. F., \& Leary, M. R. (1995). The need to belong: Desire for interpersonal attachments as a fundamental human motivation. Psychological Bulletin, 117, 497-529.

Baumeister, R. F., \& Tice, D. M. (1990). Anxiety and social exclusion. Journal of Social and Clinical Psychology, 9, 165-195.

Becker, P. E. (1998). Making inclusive communities: Congregations and the "problem" of race. Social Problems, 45, 451-452.

Beehr, T. A. (1985). The role of social support in coping with organizational stress. In T. A. Beehr \& R. S. Bhagat (Eds.), Human stress and cognition in organizations: An integrated perspective (pp. 375-398). New York: Wiley.

Beehr, T. A. (1995). Psychological stress in the workplace. New York: Routledge.

Beehr, T. A., \& McGrath, J. E. (1992). Social support, occupational stress and anxiety. Anxiety, Stress, and Coping, 5, 7-19.

Bentler, P. M. (1995). EQS structural equation modeling program manual. Encino, CA: Multivariate Software. 
Bentler, P. M., \& Bonett, D. G. (1980). Significance tests and goodness-offit in the analysis of covariance structures. Psychological Bulletin, 88, 588-606.

Bentler, P. M., \& Chou, C. P. (1986). Practical issues in structural equation modeling. In J. S. Long (Ed.), Common problems, proper solutions (pp. 161-192). Newbury Park, CA: Sage.

Bentler, P. M., \& Raykov, T. (2000). On measures of explained variance in nonrecursive structural equation models. Journal of Applied Psychology, 85, 125131.

Berndt, A. E. (1998). The Influence of model features on goodness-of-fit indices: choosing indices to evaluate your model. Unpublished doctoral dissertation, Department of Psychology, Old Dominion University, Norfolk.

Blau, P. M. (1964). Exchange and power in social life. New York: Wiley.

Blau, P. M. (1977). Inequality and heterogeneity: A primitive theory of social structure. New York: The Free Press.

Bollen, K. A. (1989). Structural equations with latent variables. New York, NY: John Wiley \& Sons.

Boomsma, A. (1982). The robustness of LISREL against small sample sizes in factor analysis models. In K. G. Jöreskog, \& H. Wold (Eds.), Systems under indirect observation: Causality, structure, prediction (Part 1, pp. 149-173). Amsterdam: North-Holland.

Brown, R. L. (1994). Efficacy of the indirect approach for estimating structural equation model with missing data: A comparison of five methods. Structural Equation Modeling: A Multidisciplinary Journal, 1, 287-316. 
Brown, S. P. (1996). A meta-analysis and review of organizational research on job involvement. Psychological Bulletin, 120, 235-255.

Burke, R. J. (1988). Some antecedents and consequences of work-family conflict. Joumal of Social Behavior and Personality, 3, 287-302.

Campbell, J. P. (1982). Editorial: Some remarks from the outgoing editor. Journal of Applied Psychology, 67, 691-700.

Cheney, G. (1983). The rhetoric of identification and the study of organizational communication. Quarterly Journal of Speech, 69, 143-158.

Clegg, C. W. (1983). Psychology of employee lateness, absence, and turnover: A Methodological critique and an empirical study. Journal of Applied Psychology, 68, 88-101.

Cohen, J. (1988). Statistical power analysis for the behavioral sciences ( $2^{\text {nd }}$ ed.). Hillsdale, $\mathrm{NJ}$ : Erlbaum.

Cooper, C. L., \& Davidson, M. J. 1982. The high cost of stress on women managers. Organizational Dynamics, 10(4), 84-93.

Cotton, J. L., Vollrath, D. A., Froggatt, K. L., Lengnick-Hall, M. L., \& Jennings, K. R. (1988). Employee participation: Diverse forms and different outcomes. Academy of Management Review, 13, 8-22.

Cox, T. H., (1990). Problems with research by organizational scholars on issues of race and ethnicity. Journal of Applied Behavioral Science, 26(1), 5-23.

Cox, T. H. (1994). Cultural diversity in organizations: Theory, research and practice. San Francisco: Berrett-Koehler. 
Cox, T. H., \& Blake, S. (1991). Managing cultural diversity: Implications for organizational competitiveness. Academy of Management Executive, 5(3), 45-55.

Craighead, W. E., Kimball, W. H., \& Rehak, R. S. (1979). Mood changes, physiological responses, and self-statements during social rejection imagery. Journal of Consulting and Clinical Psychology, 47, 385-396.

Crampton S. M. \& Wagner, J. A. (1994). Percept-percept inflation in microorganizational research: An investigation of prevalence and effect. Journal of Applied Psychology, 79, 67-76.

DeCotiis, T. A., \& Summers, T. P. (1987). A path analysis of a model of the antecedents and consequences of organizational commitment. Human Relations, 40, 445-470.

Diener, E., Larsen, R. J., \& Emmons, R. A. (1984). Person X Situations interactions: Choice of situations and congruence response models. Journal of Personality and Social Psychology, 47, 580-592.

Ding, L., Velicer, W. F., \& Harlow, L. L. (1995). Effects of estimation method, number of indicators per factor, and improper solutions on structural equation modeling fit indices. Structural Equation Modeling, 2, 119-143.

Drasgow, F. \& Miller, H. (1982). Psychometric and substantive issues in scale construction and validation. Journal of Applied Psychology, 67, 268-279.

Dreher, G. F., \& Ash, R. A. (1990). A comparative study of mentoring among men and women in managerial, professional, and technical positions. Journal of Applied Psychology, 75, 539-546. 
Dunnette, M. D., \& Motowidlo, S. K. (1982). Estimating benefits and costs of antisexist training programs in organizations. in H. J. Bernardin (Eds.), Women in the workforce (pp. 157-182). San Francisco: Prager.

Eisenberger, R., Armeli, S., Rexwinkel, B., Lynch, P. D., \& Rhoades, L. (1997). Reciprocation of perceived organizational support. Journal of Applied Psychology, 86, 42-51.

Eisenberger, R., Cummings, J., Armeli, S., \& Lynch, P. D. (1997). Perceived organizational support, discretionary treatment, and job satisfaction. Journal of Applied Psychology, 82, 812-820.

Eisenberger, R., Fasolo, P., \& Davis-LaMastro, V. (1990). Perceived organizational support and employee diligence, commitment, and innovation. Journal of Applied Psychology, 75, 51-59.

Eisenberger, R., Huntington, R., Hutchison, S., \& Sowa, D. (1986). Perceived organizational support. Journal of Applied Psychology, 71, 500-507. Ely, R. J. (1994). The effects of organizational demographics and social identity on relationships among professional women. Administrative Science Quarterly, 39, 203-238.

Famili, A., Shen, W., Weber, R., \& Simoudis, E.(1997). Data preprocessing and intelligent data analysis. Intelligent Data Analysis, 1, 1-20.

Farmer, H. S. (Ed.) (1997). Diversity and women's career development. In B. F. Okun (Series Ed.), Women's mental health and development (Vol 2). Thousand Oaks: Sage. 
Davidson, M. N. \& Ferdman, B. M. (2002). Inclusion: What can I and my organization do about it? The Industrial-Organizational Psychologist, 39 (4), 80 85.

Festinger, L. (1950). Informal social communication. Psychological Review, 57, 271-282.

Floyd, F. J., \& Widaman, K. F. (1995). Factor analysis in the development and refinement of clinical assessment instruments. Psychological Assessment, 7, 286-299.

Frone, M. R., Russell, M., \& Cooper, M. L. (1992). Antecedents and outcomes of work-family conflict: Testing a model of the work-family interface. Journal of Applied Psychology, 77, 65-78.

Gilbert, A. G., \& Ivancevich, J. M. (2000). Valuing diversity: A tale of two organizations. Academy of Management Executive, 14, 93-105.

Goldsmith, D. J. (1992). Managing conflicting goals in supportive interaction: An integrative theoretical framework. Communication Research, 19, 264-286.

Gottfredson, L. S. (1992). Dilemmas in developing diversity programs. In S. E. Jackson and Associates (Eds.), Diversity in the workplace (pp. 59-83). New York: Guilford Press.

Gould, S. (1979). An equity-exchange model of organizational involvement. Academy of Management Review, 4, 53-62.

Gouldner, A. W. (1960). The norm of reciprocity: A preliminary statement. American Sociological Review, 25, 161-178. 
Greenhaus J. H., \& Beutell, N. J. (1985). Sources of conflict between work and family roles. Academy of Management Review, 10, 76-88.

Greenhaus, J. H., \& Parasuraman, S. (1987). A work-nonwork interactive perspective of stress and its consequences. In J. M. Ivancevich \& D. C. Ganster (Eds.), Job stress: From theory to suggestion (pp. 37-60). New York: Haworth.

Greenhaus, J. H., Parasuraman, S., \& Wormley, W. M. (1990). Effects of race on organizational experiences, job performance evaluations and career outcomes. Academy of Management Journal, 33, 64-86.

Grover, S. L., \& Crooker, K. J. (1995). Who appreciates family-responsive human resource policies: The impact of family-friendly policies on the organizational attachment of parents and non-parents. Personnel Psychology, 48, 271-288.

Grusec, J. E. (1991). The socialization of altruism. in M. S. Clark (Ed.), Prosocial behavior (pp. 9-33). Newbury Park: SAGE.

Guzzo, R. A., Noonan, K.A., \& Elron, E. (1994). Expatriate managers and the psychological contract. Journal of Applied Psychology, 79, 617-626.

Hall, D. T. (1991). Career development theory in organizations. In D. Brown \& L. Brooks (Eds.), Career choice and development: Applying contemporary theories to practice (pp. 422-454). San Francisco: Jossey-Bass.

Harman, H. H. (1967). Modern factor analysis ( $2^{\text {nd }}$ ed.). Chicago: University of Chicago Press.

Hayes, B. C. (1997). The causal ordering of job satisfaction and organizational commitment on employee turnover. Paper presented at the 
Eighteenth Annual Industrial/Organizational Psychology-Organizational Behavior Graduate Conference, Roanoke, Virginia.

Hayes, B. C., Bartle, S. A., \& Major, D. A. (2002). Climate for opportunity: A conceptual model. Human Resource Management Review, 12, 1-24.

Hill, C. A. (1987). Affiliation motivation: People who need people . . but in different ways. Journal of Personality and Social Psychology, 52, 1008-1018.

Hom, P. W., Caranikas-Walker, F., Prussia, G., Dickey, L., Anderson, J., \& Griffeth, R. (1991). A meta-analytical test of a model of employee turnover. Academy of Management Proceedings, 210-214.

Hopkins, W. E., Sterkel-Powell, K., \& Hopkins, S. A. (1994). Training priorities for a diverse workforce. Public Personnel Management, 23, 429-435.

House, J. S. (1981). Work stress and social support. Reading, MA: Addison-Wesley.

Hutchison, S. (1997). A path model of perceived organizational support. Journal of Social Behavior and Personality, 12, 159-174.

Hutchison, S., \& Garstka, M. L. (1996). Sources of perceived organizational support: Goal setting and feedback. Journal of Applied Social Psychology, 26, 1351-1366.

Ibarra, H. (1993). Personal networks of women and minorities in management: A conceptual framework. Academy of Management Review, 18, $56-87$.

Jackson, B. W., LaFasto, F., Schultz, H. G., \& Kelly, D. (1992). Diversity. Human Resource Management, 31, 21-34. 
Jackson, S. E., \& Alverez, E. B. (1993). Working through diversity as a strategic imperative. In S. E. Jackson (Ed.), Diversity in the workplace: Human resource initiatives (pp. 13-29). New York: Guilford Press.

Jackson, S. E., Stone, V. K. \& Alvarez, E. D. (1993). Socialization amidst diversity: Impact of demographics on work team old-timers and newcomers. In L. L. Cummings and B. M. Shaw (Eds.), Research in organizational behavior (Vol. 15, pp. 45-109). Greenwich, CT: JAl Press.

Jacobsen, D. (1999). Inclusive and discerning? (exclusivity of US churches). The Christian Century, 116, 440-441.

James, W. (1890). The principles of psychology (Vol. 1). New York: Henry Holt and Company.

James, L. R., Mulaik, S. S., \& Brett, J. M. (1982). Causal analysis: Assumptions, models, and data. Beverly Hills, CA: Sage.

Johnston, W. B., \& Packer, A. E. (1987). Workforce 2000: Work and workers for the $21^{\text {st }}$ century. Indianapolis, IN: Hudson Institute.

Jones, B., Flynn, D. M., \& Kelloway, E. K. (1995). Perception of support from the organization in relation to work stress, satisfaction, and commitment. In S. L. Sauter \& L. R. Murphy (Eds.), Organizational risk factors for job stress (pp. 41-52). Washington, DC: American Psychological Association.

Kahn, W. A. (1990). Psychological conditions of personal engagement and disengagement at work. Academy of Management Journal, 33, 692-724. 
Kenny, D. A., Kashy, D. A., \& Bolger, N. (1998). Data analysis in social psychology. In D. Gilbert, S. Fiske, \& G. Lindzey (Eds.), Handbook of social psychology ( $4^{\text {th }}$ ed., Vol. 1, pp. 233-265). Boston, MA: McGraw-Hill.

Kline, R. B. (1998). Principles and practices of structural equation modeling. New York: Guilford.

Konrad, A. M., \& Linnehan, F. (1995). Formalized HRM structures: Coordinating equal employment opportunity or concealing organizational practices? Academy of Management Journal, 38, 787-820.

Kopelman, R. E., Greenhaus, J. H., \& Connolly, T. F. (1983). A model of work, family, and interrole conflict: A construct validation study. Organizational Behavior and Human Performance, 32, 198-215.

Kottke, J. L., \& Sharafinski, C. E. (1988). Measuring perceived supervisory and organizational support. Educational and Psychological Measurement, 48, 1075-1079.

Kram, K. E. (1983). Phases of the mentor relationship. Academy of Management Journal, 26, 608-625.

Kram, K. E., \& Isabella, L. A. (1985). Mentoring alternatives: The role of peer relationships in career development. Academy of Management Journal, 28, $110-132$.

Kravitz, D. A., Harrison, D. A., Turner, M. E., Levine, E. L., Chaves, W., Brannick, M. T., Denning, D. L., Russell, C. J., \& Conrad, M. A. (1996). A review of psychological and behavioral research on affirmative action [On-line]. Available: http://cmit.unomaha.edu/TIP/ SIOP/siopsaartoc.html. 
Lakoff, R. (1975). Language and woman's place. New York: Harper \& Row.

Lambert, S. J. (2000). Added benefits: The link between work-life benefits and organizational citizenship behavior. Academy of Management Journal, 43, 801-815.

Lance, C. E. (1991). Evaluation of a structural model relating job satisfaction, organizational commitment, and precursors to voluntary turnover. Multivariate Behavioral Research, 26, 137-162.

Lawler, E. E. (1992). The ultimate advantage: Creating high-involvement organizations. San Francisco: Jossey-Bass.

Lawler, E. E. (1995). Creating high performance organizations. San Francisco: Jossey-Bass.

Leary, M. R. (1990). Responses to social exclusion: Social anxiety, jealousy, loneliness, depression, and low selfesteem. Journal of Social and Clinical Psychology, 9, 221-229.

Leary, M. R., \& Downs, D. L. (1995). Interpersonal functions of the selfesteem motive: The self-esteem system as a sociometer. In M. Kernis (Ed.), Efficacy, agency, and selfesteem (pp. 123-144). New York: Plenum.

Leary, M. R., Haupt, A. L., Strausser, K. S., \& Chokel, J. T. (1998). Calibrating the sociometer. The relationship between interpersonal appraisal and state self-esteem. Journal of Personality and Social Psychology, 74, 1290-1299. 
Leary, M. R., Tambor, E. S., Terdal, S. K. \& Downs, D. L. (1995). Selfesteem as an interpersonal monitor. The sociometer hypothesis. Joumal of Personality and Social Psychology, 68, 518-530.

Levinson, H. (1965). Reciprocation: The relationship between man and organization. Administrative Science Quarterly, 9, 370-390.

Lewin. K. (1943). Defining the "field at a given time." Psychological Review, 50, 292-310.

Likert, R. L. (1967). The human organization. New York: McGraw-Hill.

Little, R. J. (1993). Pattern-mixture models for multivariate incomplete data. Journal of the American Statistical Association, 88, 125-124.

Little, R. J., \& Rubin, D. A. (1987). Statistical analysis with missing data. New York: John Wiley and Sons.

Long, J. S. (1983). Confirmatory factor analysis. Sage University Paper Series on Quantitative Application in the Social Sciences, 7-33. Beverly Hills and London: Sage Publications.

MacCallum, R.C., Browne, M. W., \& Sugawara, H. M. (1996). Power analysis and determination of sample size for covariance structure modeling. Psychological Methods, 1, 130-149.

Major, D. A., Kozlowski, S. W., Chao, G. T., \& Gardner, P. D. (1995). A longitudinal investigation of newcomer expectations, early socialization outcomes, and the moderating effects of role development factors. Journal of Applied Psychology, 80, 418-431. 
Marsh, H. W., Balla, J. R., \& McDonald, R. P. (1988). Goodness-of-fit indexes in confirmatory factor analysis: The effect of sample size. Psychological Bulletin, 103, 391-410.

Maslow, A. H. (1954). Motivation and personality. New York: Harper \& Row.

Mathieu, J. E. (1991). A cross-level nonrecursive model of the antecedents of organizational commitment and satisfaction. Journal of Applied Psychology, 76, 607-618.

Mathieu, J. E., \& Zajac, D. M. (1990). A review and meta-analysis of the antecedents, correlates, and consequences of organizational commitment. Psychological Bulletin, 108(2), 171-194.

McClelland, D. (1985). Human motivation. Glennville, IL: Scott Foresman.

McCune, J. C. (1996). Diversity training: A competitive weapon. Management Review, 85(6), 25-29.

McDougall, W. (1908). Introduction to social psychology. London: Methuen.

McGregor, D. (1960). The human side of enterprise. New York: McGrawHill.

Mclntosh, N. J. (1991). Identification and investigation of properties of social support. Journal of Organizational Behavior, 12, 201-217.

Meyer, J. P., Allen, N. J., \& Smith, C. A., (1993). Commitment to organizations and occupations: Extension and test of a three-component conceptualization. Journal of Applied Psychology, 78, 538-551. 
Miller, F. A. (1998). Strategic culture change: The door to achieving high performance and inclusion. Public Personnel Management, 27(2), 151-161.

Miller, F. A., \& Katz, J. H. (1995). Cultural diversity as a developmental process: The path from monocultural club to inclusive organization. In The 1995 annual: Vol. 2, Consulting (pp. 1-17). San Diego: Pfeiffer \& Co.

Miller, K. I., \& Monge, P. R. (1986). Participation, satisfaction, and productivity: A meta-analytic review. Academy of Management Journal, 29, 727753.

Mobley, W. H., Griffeth, R. W., Hand, H. H., \& Meglino, B. M. (1979). A review and conceptual analysis of the employee turnover process. Psychological Bulletin, 86, 493-522.

Morrison, E. W. (1993a). Longitudinal study of the effects of information seeking on newcomer socialization. Journal of Applied Psychology, 79, 173-183.

Morrison, E. W. (1993b). Newcomer information seeking: Exploring types, modes, sources, and outcomes. Academy of Management Journal, 36, 557-589.

Mowday, R. T., Porter, L. W., \& Steers, R. M., (1982). Employeeorganizational linkages: The psychology of commitment, absenteeism, and turnover. New York: Academic Press.

Mowday, R. T., Steers, R. M., \& Porter, L. W. (1979). The measurement of organizational commitment. Journal of Vocational Behavior, 14, 224-247.

Meyer, J. P., Allen, N. J., \& Smith, C. A., (1993). Commitment to organizational and occupations: Extension and test of a three-component conceptualization. Journal of Applied Psychology, 78, 538-551. 
Murrell, A. J., Dietz-Uhler, B. L., Dovidio, J. F., Gaertner, S. L., \& Drout, C. (1994). Aversive racism and resistance to affirmative action: Perceptions of justice are not necessarily colorblind. Basic and Applied Social Psychology, 15, 71-86.

Nacoste, R. W. (1987). But do they care about fairness? The dynamics of preferential treatment and minority interest. Basic and Applied Social Psychology, 8, 177-191.

Netemeyer, R. G., Boles, J. S., \& McMurrian, R. (1996). Development and validation of work-family conflict and family-work conflict. Journal of Applied Psychology, 81, 400-410.

Newell, C. E., Rosenfeld, P., \& Culbertson, A. L. (1995). Sexual harassment experiences and equal opportunity perceptions of Navy women. Sex Roles, 32, 159-168.

Nezlek, J. B., Kowalski, R. M., Leary, M. R., Blevins, T., \& Holgate, S. (1997). Personality moderators of reactions to interpersonal rejection: Depression and trait self-esteem. Personality \& Social Psychology Bulletin, 23, 1235-1245.

Olsson, U. H., Foss, T., \& Howell, R. D. (1999). Theoretic fit and empirical fit: The performance of maximum likelihood versus generalized least squares estimation in structural equation modeling. Multivariate Behavioral Research, 34 (1), 31-58.

Olsson, U. H., Foss, T., Troye, S. V., \& Howell, R. D. (2000). The performance of ML, GLS, and WLS estimation in structural equation modeling 
under conditions of misspecification and nonnormality. Structural Equation Modeling, 7, 557-595.

Ostroff, C., \& Kozlowski, S. W. (1992). Organizational socialization as a learning process: The role of information acquisition. Personnel Psychology, 45, 849-874.

Patton, J. M., \& Townsend, B. L. (1997). Creating inclusive environments for African American children and youth with gifts and talents. Roeper Review, $20,13-18$.

Pettigrew, T. F., \& Martin, J. (1989). Organizational inclusion of minority groups: A social psychological analysis. In J. P. Van Oudenhoven \& T. M. Willemsen (Eds.), Ethnic minorities: Social psychological perspectives. Berwyn, PA: Swets North America.

Podsakoff, P., \& Organ, D. (1986). Self-reports in organizational research: Problems and prospects. Journal of Management, 12, 531-544.

Prasad, A. (2001). Understanding workplace empowerment as inclusion. The Journal of Applied Behavioral Science, 37, 51-69.

Putti, J. M., Aryee, S., \& Phua, J. (1990). Communication relationship, satisfaction and organizational commitment. Group and Organizational Studies, $51,44-52$.

Ritchie, J. B., \& Miles, R. E. (1970). An analysis of quantity and quality of participation as mediating variables in the participation decision making process. Personnel Psychology, 23, 347-359. 
Riordan, C. M., \& Shore, L. M. (1997). Demographic diversity and employee attitudes: An empirical examination of relational demography within work units. Journal of Applied Psychology, 82, 342-358.

Romeu, J. L., \& Ozturk, A. (1993). A comparative study of goodness-of-fit tests for multivariate normality. Journal of Multivariate Analysis, 46, 309-334.

Rosin, H., \& Korabik, K. (1995). Organizational experiences and propensity to leave: A Multivariate investigation of men and women managers. Journal of Vocational Behavior, 46, 1-16.

Rousseau, D. M. (1989). Psychological and implied contracts in organizations. Employee Rights and Responsibilities Journal, 2, 121-139.

Rynes, S., \& Rosen, B. (1995). A field survey of factors affecting the adoption and perceived success of diversity training. Personnel Psychology, 48, 247-270.

Salancik, G. R., \& Pfeffer, J. (1978). A social information processing approach to job attitudes and task design. Administrative Science Quarterly, 23, 224-253.

Salend, S. J. (1994). Effective mainstreaming: Creating inclusive classrooms. New York: Macmillan.

Sanchez, J. I., \& Brock, P. (1996). Outcomes of perceived discrimination among Hispanic employees: Is diversity management a luxury or a necessity? Academy of Management Journal, 39, 704-719. 
Sarason, I. G., Levine, H. M., Basham, R. B., \& Sarason, B. R. (1983). Assessing social support: The social support questionnaire. Journal of Personality and Social Psychology, 44, 127-139.

Schafer, J.L. (1997). Analysis of Incomplete Multivariate Data. Book number 72 in the Chapman \& Hall series Monographs on Statistics and Applied Probability. London: Chapman \& Hall.

Schappe, S. P. (1996). Bridging the gap between procedural knowledge and positive employee attitudes: Procedural justice as keystone. Group and Organizational Management, 21, 337-364.

Schneider, B., \& Reichers, A. E. (1983). On the etiology of climates. Personnel Psychology, 36, 19-39.

Schneider, K. T., Swan, S., \& Fitzgerald, L. F. (1997). Job related and psychological effects of sexual harassment in the workplace: Empirical evidence from two organizations. Journal of Applied Psychology, 82, 401-417.

Schriesheim, C. (1979). The similarity of individual directed and group directed leader behavior descriptions. Academy of Management Journal, 22, 345-355.

Schumacker, R. E., \& Lomax, R. G. (1996). A beginner's guide to structural equation modeling. Mahwah, NJ: Lawrence Eribaum Associates.

Settoon, R. P., Bennett, N., \& Liden, R. C. (1996). Social exchange in organizations: Perceived organizational support, leader-member exchange, and employee reciprocity. Journal of Applied Psychology, 81, $219-227$. 
Sheldon, K. M., Elliot, A. J., Kim, Y., \& Kasser, T. (2001). What is satisfying about satisfying events? Testing 10 candidate psychological needs. Journal of Personality and Social Psychology, 80, 325-339.

Shore, L. M., \& Tetrick, L. E. (1991). A construct validity study of the survey of perceived organizational support. Journal of Applied Psychology, 76, $637-643$.

Shore, L. M., \& Wayne, S. J. (1993). Commitment and employee behavior: Comparison of affective commitment and continuance commitment with perceived organizational support. Joumal of Applied Psychology, 78, 774-780.

Shulman, S., \& Darity, W., Jr. (1989). The question of discrimination: Racial inequities in the U.S. labor market. Middletown, CT: Wesleyan University Press.

Smith, P. C., Kendall, L. M., \& Hulin, C. L. (1969). The measurement of satisfaction in work and retirement. Chicago, IL: Rand McNally.

Spector, P. E. (1987). Method variance as an artifact in self-reported affect and perceptions at work: Myth or significant problem? Journal of Applied Psychology, 72, 438-443.

Stainback, S., \& Stainback, W. (1990). Support networks for inclusive schooling: Interdependent, integrated education. Baltimore, MD: Brookes.

Steiger, J.H. (1990). Structural model evaluation and modification: An interval estimation approach. Multivariate Behavioral Research, 25, 173-180. 
Tanaka, J. S. (1987). "How big is big enough?" Sample size and goodness of fit in structural equation models with latent variables. Child Development, 58, 134-146.

Tett, R. P., \& Meyer, J. P., (1993). Job satisfaction, organizational commitment, turnover intentions, and turnover. Path analyses based on metaanalytic findings. Personnel Psychology, 46, 259-293.

Thomas, R. R. (1990). From Affirmative Action to affirming diversity. Harvard Business Review, 90, 107-117.

Thomas, R. R. (1992). Managing diversity: A conceptual framework. In S. E. Jackson and Associates, Work through diversity: Human resources initiatives. New York: Guildford Press.

Thompson, C. A., Beauvais, L. L., \& Lyness, K. S. (1999). When workfamily benefits are not enough: The influence of work-family culture on benefit utilization, organizational attachment, and work-family conflict. Journal of Vocational Behavior, 54, 392-415.

Triandis, H. C., Kurowski, L. L., \& Gelfand, M. J. (1994). Workplace diversity. In H. C., Triandis, M. Dunnette, \& L. M. Hough (Eds.), Handbook of industrial and organizational psychology (pp. 770-827). Palo Alto, CA: Consulting Psychologists Press.

Tucker, L. R., \& Lewis, C. (1973). A reliability coefficient for maximum likelihood factor analysis. Psychometrika, 38, 1-10.

Turner, J. E., Hayes, B. C., Bartle, S., \& Green, A. P. (1999). OCBs, organizational spontaneity, prosocial behavior, contextual performance: Cleaning 
up the conceptual morass. Poster presented at the $14^{\text {th }}$ Annual Conference for the Society for Industrial and Organizational Psychology. Atlanta, Georgia.

Vroom, H. V. (1960). Some personality determinants of the effects of participation. Englewood Cliffs, NJ: Prentice-Hall, Inc.

Wagner, J. A. (1994). Participation's effects on performance and satisfaction: A reconsideration of research evidence. Academy of Management Review, 19, 312-330.

Wagner, J. A., \& Gooding, R. Z. (1987). Shared influence and organizational behavior. A meta-analysis of situational variables expected to moderate participation-outcome relationships. Academy of Management Joumal, $30,524-541$.

Wayne, S. J., Shore, L. M., \& Liden, R. C. (1997). Perceived organizational support and leader-member exchange: A social exchange perspective. Academy of Management Journal, 40, 82-111.

Wentling, R., \& Palma-Rivas (1997). Diversity in the workforce series Report \#1: Diversity in the workforce: A literature review. National Center for Research in Vocation Education. Grant \# V051A30003-97AV051A30004-97A. Westin, A. F. (1992). Two key factors that belong in a macroergonomic analysis of electronic monitoring: Employee perceptions of fairness and the climate of organizational trust or distrust. Applied Ergonomics, 23, 35-42.

Williams, L. J., Cote, J. A., \& Buckley, M. R., (1989). The lack of method variance in self-reported affect and perceptions at work: Reality or artifact? Journal of Applied Psychology, 74, 462-468. 
Williams, L. J., \& Hazer, J. T. (1986). Antecedents and consequences of satisfaction and commitment in turnover models: $A$ reanalysis using latent variable structural equation modeling. Journal of Applied Psychology, 71, 219231. 


\section{APPENDIXA}

\section{SCALE AND SURVEY INFORMATION}

Table A1

Factor Loadings for all Measures Included in Study 1

\begin{tabular}{|c|c|}
\hline Statement & $\begin{array}{l}\text { Factor } \\
\text { loading }\end{array}$ \\
\hline 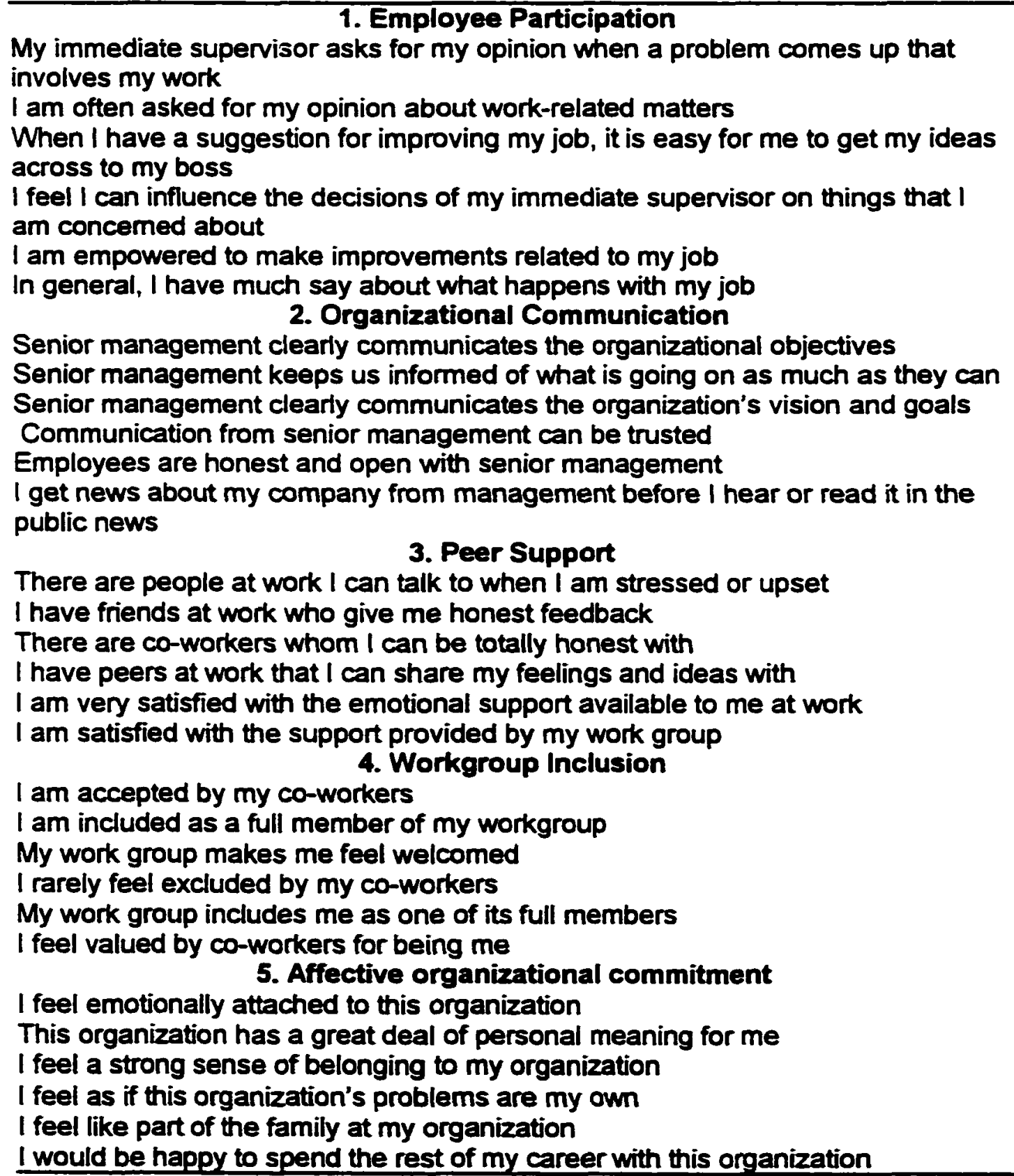 & $\begin{array}{c}.76 \\
\\
.75 \\
.72 \\
.62 \\
\text { Factor } 2 \\
.83 \\
.82 \\
.82 \\
.66 \\
.64 \\
\\
.64 \\
\text { Factor } 3 \\
.84 \\
.83 \\
.81 \\
.77 \\
.70 \\
.70 \\
\text { Factor } 4 \\
.79 \\
.78 \\
.76 \\
.76 \\
.75 \\
.62 \\
\text { Factor } 5 \\
.87 \\
.76 \\
.68 \\
.66 \\
.65 \\
.52 \\
\end{array}$ \\
\hline
\end{tabular}

(table continues) 
Table A1 (continued)

Factor Loadings for all Measures Included in Study 1

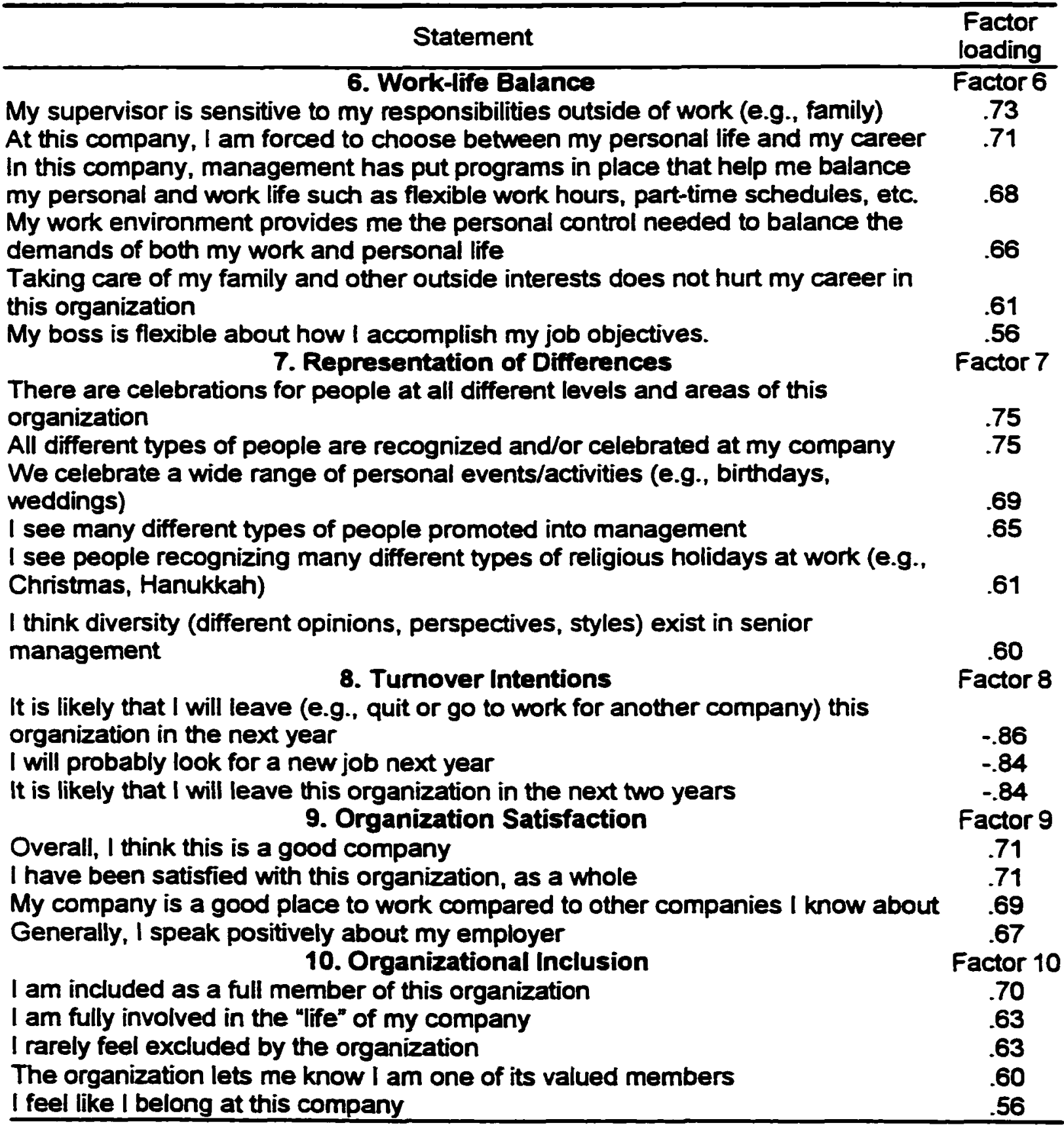

Note: All factor loadings greater than .50 are shown in Table A1. 
Table A2

Survey packet for Study 2

Colleagues,

November 16, 2001

Dean X's support of this survey reflects his commitment to faculty and staff development at Company $X$. We will use this to gather information to assist various departments in developing programs beneficial to your professional development. Your opinions are very important as we analyze and plan programs for your benefit, recognition, and advancement. Bryan Hayes, a doctoral student in psychology at ODU, is assisting in our efforts. He researches communication, diversity and inclusion in the workplace as it relates to career advancement and satisfaction.

Participation in this study provides vital information. It is an opportunity for you to express opinions and give us information to determine the scope necessary to ensure a systematic and comprehensive professional development program for all staff and faculty.

In appreciation of the time you must use to complete the survey, the researchers will use funds designated to aid in data collection to make a donation of $\$ 5$ for each returned survey to the American Red Cross-Company $X$ relief effort for families wounded in New York City by the events of September 11, 2001. With your participation in conjunction with everyone else, the total donation could be significant.

Please know that all your responses will remain anonymous and confidential; no person will know how you answered the questions.

Read the instructions carefully for each section of the survey and answer all questions. Please return your completed survey in the enclosed envelope by November 19, 2001.

If you have questions, call $X$ at $x \alpha x-x x x x$. Specific results will be provided upon request.

Your participation and contribution in providing information to aid our program development is greatly appreciated.

Sincerely,

X, M.D. X, Ph.D.

(table continues) 
Table A2 (continued)

Survey packet for Study 2

Survey

INSTRUCTIONS: You will be asked to respond to statements about work experiences and attitudes.

When a question refers to Company $X$ or the "organization," think of Company $X$ as a whole.

When a question refers to "leadership" or "senior leadership," think of those persons at the highest levels of EVMS.

When a question refers to your "immediate supervisor," think of the one you report directly to (the one who writes your yearly evaluation).

When a question refers to your "co-workers" or "workgroup," think of those people you work most closely with. This is the same as your work team.

\section{A description is given at the beginning of each set of questions}

Read each statement and rate the degree to which you agree or disagree with the statement using the scale below.

\begin{tabular}{|c|c|c|c|c|}
\hline $\begin{array}{c}\text { Strongly } \\
\text { Disagee }\end{array}$ & $\begin{array}{c}\text { Sightly } \\
\text { Disagree }\end{array}$ & $\begin{array}{c}\text { No } \\
\text { Opinion }\end{array}$ & $\begin{array}{c}\text { Sightly } \\
\text { Agree }\end{array}$ & $\begin{array}{c}\text { Strangly } \\
\text { Agree }\end{array}$ \\
\hline 1 & 2 & 3 & 4 & 5 \\
\hline
\end{tabular}

\begin{tabular}{|c|c|c|}
\hline I & $\begin{array}{l}\text { Questions in this section refer to the degree to which you feel you are } \\
\text { induded as a full member of your immediate workgrap }\end{array}$ & $\begin{array}{l}\text { Cirde only } \\
\text { one response }\end{array}$ \\
\hline 1. & Ifeel like I belong in this warkgrap & 12345 \\
\hline 2 & My workgrap makes me feel welcamed & 12345 \\
\hline 3. & My workgrap indudes me as one of its full mentbers & 12345 \\
\hline 4. & I rarely feel excluded by my coworkers & 12345 \\
\hline 5. & I am accepted by my oo-workers & 12345 \\
\hline 6. & I feel valued by coworkers for being me & 12345 \\
\hline 7. & I feel a strong sense of association with my workgrap & 12345 \\
\hline 8. & I am induded as a full member of my workgrap & 12345 \\
\hline
\end{tabular}

(table continues) 
Table A2 (continued)

Survey packet for Study 2

\begin{tabular}{|c|c|c|c|c|c|c|}
\hline & $\begin{array}{l}\text { Strangly } \\
\text { Disagree } \\
1\end{array}$ & $\begin{array}{l}\text { Slightly } \\
\text { Disegree } \\
2\end{array}$ & $\begin{array}{c}\text { No } \\
\text { Opinion } \\
3\end{array}$ & $\begin{array}{l}\text { Sightly } \\
\text { Agree } \\
4\end{array}$ & \multicolumn{2}{|c|}{$\begin{array}{l}\text { Strangly } \\
\text { Agree } \\
5\end{array}$} \\
\hline & \multicolumn{5}{|c|}{$\begin{array}{l}\text { Questions in this section refer to the degree to which you feel you are } \\
\text { included as a full member of the overall organization }\end{array}$} & $\begin{array}{l}\text { Circle only } \\
\text { one response }\end{array}$ \\
\hline & \multicolumn{5}{|c|}{ I feel like I belong at Company $X$} & 12345 \\
\hline 0. & \multicolumn{5}{|c|}{ My organization makes me feel welcomed } & 12345 \\
\hline 14. & \multicolumn{5}{|c|}{ I am included as a full member of this organization } & 12345 \\
\hline 12. & \multicolumn{5}{|c|}{ I rarely feel excluded by the organization } & 12345 \\
\hline 13. & \multicolumn{5}{|c|}{ I am accepted by my organization } & 12345 \\
\hline 14. & \multicolumn{5}{|c|}{ I am fully involved in the "life" of Company $X$} & 12345 \\
\hline 15. & \multicolumn{5}{|c|}{ The organization lets me know I am one of its valued members } & 12345 \\
\hline 16. & \multicolumn{5}{|c|}{ I feel a strong sense of association with Company $X$} & 12345 \\
\hline III & \multicolumn{5}{|c|}{$\begin{array}{c}\text { Questions in this section refer to your level of say and influence } \\
\text { regarding what goes on in your job }\end{array}$} & $\begin{array}{l}\text { Circle only } \\
\text { oneresponse }\end{array}$ \\
\hline 17. & \multicolumn{5}{|c|}{ In general, I have much say about what happens with my job } & 12345 \\
\hline 18. & \multicolumn{5}{|c|}{$\begin{array}{l}\text { I feel I can influence the decisions of my immediate supervisor on } \\
\text { things that I am concerned about }\end{array}$} & 12345 \\
\hline 19. & \multicolumn{5}{|c|}{$\begin{array}{l}\text { My immediate supervisor asks for my opinion when a problem } \\
\text { comes up that involves my work }\end{array}$} & 12345 \\
\hline 20. & \multicolumn{5}{|c|}{$\begin{array}{l}\text { When I have a suggestion for improving my job, it is easy for me } \\
\text { to get my ideas across to my boss }\end{array}$} & 12345 \\
\hline 21. & \multicolumn{5}{|c|}{ I am often asked for my opinion about work-related matters } & 12345 \\
\hline 22. & \multicolumn{5}{|c|}{ I am empowered to make improvements related to my job } & 12345 \\
\hline N & \multicolumn{5}{|c|}{$\begin{array}{l}\text { Questions in this section refer to the availability of } \\
\text { sources of support at work }\end{array}$} & $\begin{array}{l}\text { Circle only } \\
\text { oneresponse }\end{array}$ \\
\hline 23. & \multicolumn{5}{|c|}{ I have peers at work that I can share my feelings and ideas with } & 12345 \\
\hline 24. & \multicolumn{5}{|c|}{ There are people at work I can talk to when I am stressed or upset } & 12345 \\
\hline 25. & \multicolumn{5}{|c|}{ I have friends at work who give me honest feedback } & 12345 \\
\hline 26. & \multicolumn{5}{|c|}{ There are co-workers whom I can be totally honest with } & 12345 \\
\hline 27. & \multicolumn{5}{|c|}{ I am very satisfied with the emotional support available to me } & 12345 \\
\hline 28. & \multicolumn{5}{|c|}{ I am satisfied with the support provided by my work group } & 12345 \\
\hline
\end{tabular}

(table continues) 
Table A2 (continued)

Survey packet for Study 2

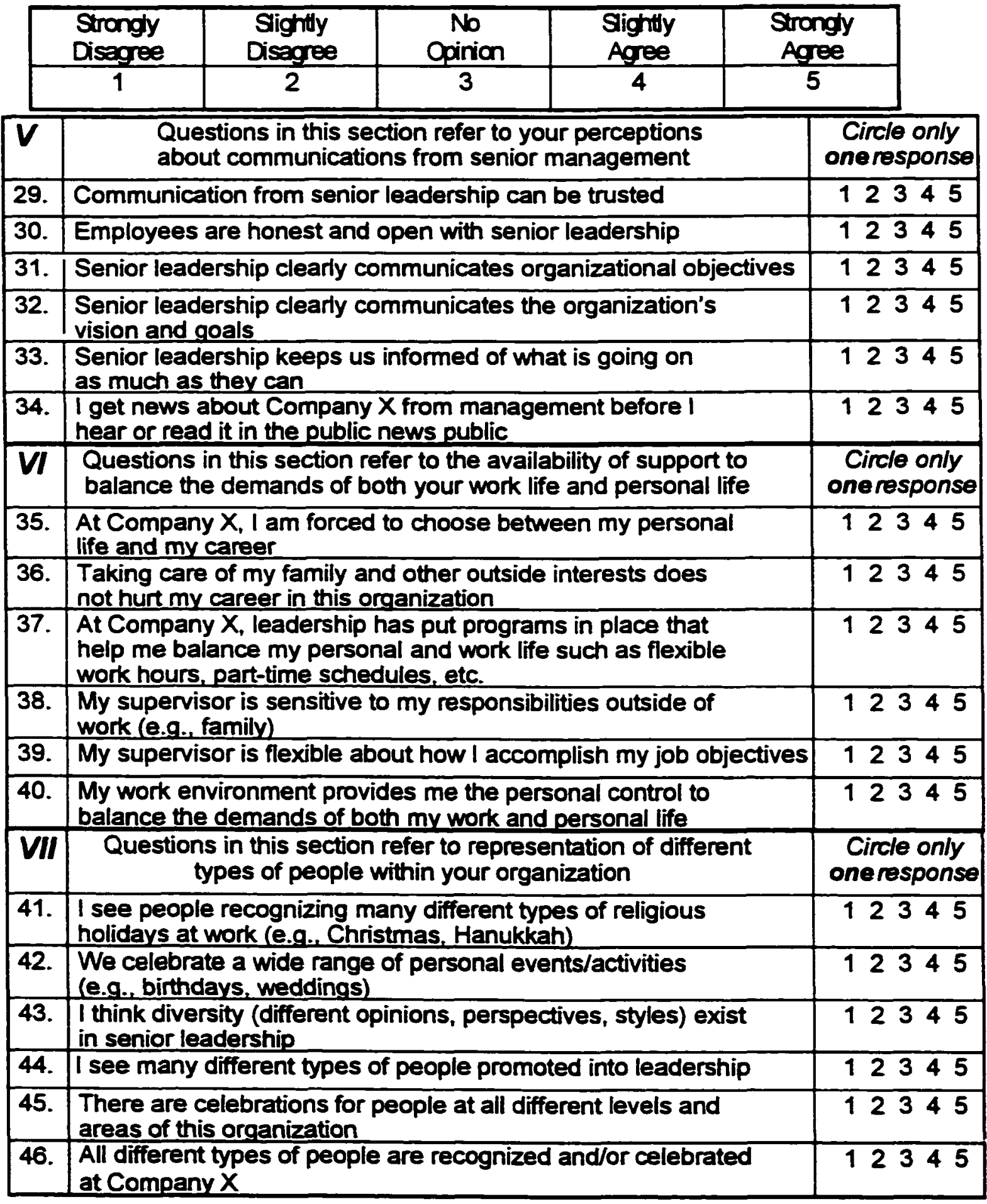

(table continues) 
Table A2 (continued)

Survey packet for Study 2

\begin{tabular}{|c|c|c|c|c|c|c|}
\hline & $\begin{array}{l}\text { Strongly } \\
\text { Disagree }\end{array}$ & $\begin{array}{l}\text { Sightly } \\
\text { Disagree }\end{array}$ & $\begin{array}{c}\text { No } \\
\text { Oainian }\end{array}$ & $\begin{array}{l}\text { Slightly } \\
\text { Agree }\end{array}$ & \multicolumn{2}{|c|}{$\begin{array}{l}\text { Strongly } \\
\text { Agree }\end{array}$} \\
\hline & 1 & 2 & 3 & 4 & & \\
\hline VIII & \multicolumn{5}{|c|}{$\begin{array}{l}\text { Questions in this section refer to your overall feelings } \\
\text { about Company } X\end{array}$} & $\begin{array}{l}\text { Circle only } \\
\text { oneresponse }\end{array}$ \\
\hline 47. & \multicolumn{5}{|c|}{ I would be happy to spend the rest of my career with Company $X$} & 12345 \\
\hline 48. & \multicolumn{5}{|c|}{ I feel as if this organization's problems are my own } & 12345 \\
\hline 49. & \multicolumn{5}{|c|}{ I feel a strong sense of belonging to Company $X$} & 12345 \\
\hline 50. & \multicolumn{5}{|c|}{ I fesl emotionally attached to Company $X$} & 12345 \\
\hline 51. & \multicolumn{5}{|c|}{ I feel like part of the family at Company $X$} & 12345 \\
\hline 52. & \multicolumn{5}{|c|}{ This organization has a great deal of personal meaning for me } & 12345 \\
\hline$D$ & \multicolumn{5}{|c|}{$\begin{array}{l}\text { Questions in this section refer to your overall satisfaction } \\
\text { with Company } X \text { as a whole }\end{array}$} & $\begin{array}{l}\text { Circle only } \\
\text { oneresponse }\end{array}$ \\
\hline 53. & \multicolumn{5}{|c|}{$\begin{array}{l}\text { Company } X \text { is a good place to work compared to other } \\
\text { organizations I know about }\end{array}$} & 12345 \\
\hline 54. & \multicolumn{5}{|c|}{ Overall, I think this is a good organization } & 12345 \\
\hline 55. & \multicolumn{5}{|c|}{ I have been satisfied with this organization, as a whole } & 12345 \\
\hline 56. & \multicolumn{5}{|c|}{ Generally, I speak positively about Company $X$} & 12345 \\
\hline $\bar{x}$ & \multicolumn{5}{|c|}{$\begin{array}{l}\text { Questions in this section refer to your overall satisfaction with } \\
\text { your immediate workgroup }\end{array}$} & $\begin{array}{l}\text { Circle only } \\
\text { oneresponse }\end{array}$ \\
\hline 57. & \multicolumn{5}{|c|}{ I have been satisfied with my immediate workgroup, as a whole } & 12345 \\
\hline 58. & \multicolumn{5}{|c|}{ Overall, I think this is a good workgroup } & 12345 \\
\hline 59. & \multicolumn{5}{|c|}{ Generally, I speak positively about my immediate co-workers } & 12345 \\
\hline 60. & \multicolumn{5}{|c|}{ Being part of my group is a good place to work } & 12345 \\
\hline $\mathbf{X I}$ & \multicolumn{5}{|c|}{$\begin{array}{l}\text { Questions in this section refer to the likelihood of you leaving } \\
\text { your job in the next one to two years }\end{array}$} & $\begin{array}{l}\text { Circle only } \\
\text { oneresponse }\end{array}$ \\
\hline 61. & \multicolumn{5}{|c|}{$\begin{array}{l}\text { It is likely that I will leave (e.g., quit or go to work for another } \\
\text { organization) Company } X \text { in the next year }\end{array}$} & 12345 \\
\hline 62. & \multicolumn{5}{|c|}{ It is likely that I will leave Company $X$ in the next two years } & 12345 \\
\hline 63. & \multicolumn{5}{|c|}{ I will probably look for a new job next year } & 12345 \\
\hline
\end{tabular}

(table continues) 
Table A2 (continued)

Survey packet for Study 2

Please answer the following demographic questions. These questions will be used for descriptive purposes only.

1. How many years have you been employed at Company $X$ ?

2. In what area or department within Company $X$ do you work?

3. What is your position or level within Company $X$ (circle one)?

a. Executive/Administrative

b. Faculty (including Chairs and Deans)

c. Professional, Non-Faculty

d. Clinician - mid level providers (nurse practitioners)

e. Technical/paraprofessional

f. Clerical

g. Skilled/Craft Workers

h. Service/Maintenance

i. Work Study

j. Residents \& Psychology Interns

k. Fellows

I. Other

4. Including you, how many people are in your immediate workgroup (how many peers do you work with on a regular basis)?

5. Are you: male female (please check one)

6. Please provide your age: years

7. What is your race (circle all that apply)?

a. Black or African American

c. White (non-Hispanic or Latino)

b. Asian or Pacific Islander

e. Alaska or Hawaiian Native, or North American Indian

f. Other (please specify):

Thank you once again for participating in this research study!

Any additional comments from you are welcomed. 


\section{APPENDIX B}

\section{CONFIRMATORY FACTOR ANALYSIS}

Table B1

Workgroup Inclusion: Standardized Factor Loadings (SFL), Measurement Error Variances (MEV), And Item Reliability $\left(R^{2}\right)$

\begin{tabular}{ccccccc}
\hline & \multicolumn{3}{c}{ Maximum Likelihood } & \multicolumn{3}{c}{ Generalized Least Squares } \\
\cline { 2 - 7 } Item & SFL & MEV & $R^{2}$ & SFL & MEV & $R^{2}$ \\
\hline 1 & .85 & .25 & .73 & .87 & .21 & .76 \\
2 & .87 & .20 & .76 & .89 & .16 & .80 \\
3 & .89 & .22 & .80 & .92 & .16 & .85 \\
4 & .78 & .52 & .61 & .79 & .49 & .62 \\
5 & .83 & .20 & .68 & .87 & .14 & .75 \\
6 & .83 & .33 & .68 & .87 & .24 & .75 \\
7 & .90 & .22 & .80 & .91 & .20 & .82 \\
8 & .91 & .19 & .83 & .93 & .14 & .87 \\
\hline
\end{tabular}

Note. $N=609$. All factor loadings and measurement error variances are significant $(p<.05)$. ML chi-square $(d f=20, p<.05)=278.03$; GLS chi-square $(d f=20, p<.05)=210.48$. Composite reliability estimate $=.84$.

Table B2

Organizational Inclusion: Standardized Factor Loadings (SFL), Measurement Error Variances (MEV), And Item Reliability $\left(R^{2}\right)$

\begin{tabular}{|c|c|c|c|c|c|c|}
\hline \multirow[b]{2}{*}{ Item } & \multicolumn{3}{|c|}{ Maximum Likelihood } & \multicolumn{3}{|c|}{ Generalized Least Squares } \\
\hline & $\overline{\mathrm{SFL}}$ & MEV & $R^{2}$ & $\overline{\text { SFL }}$ & MEV & $R^{2}$ \\
\hline 9 & .82 & .37 & .68 & .87 & .27 & .75 \\
\hline 10 & .89 & .28 & .79 & .90 & .25 & .81 \\
\hline 11 & .87 & .35 & .76 & .89 & .27 & .80 \\
\hline 12 & .84 & .43 & .71 & .85 & .40 & .73 \\
\hline 13 & .87 & .27 & .76 & .88 & .26 & .77 \\
\hline 14 & .76 & 67 & .57 & .81 & .51 & .65 \\
\hline 15 & .79 & .73 & 62 & .84 & .50 & .71 \\
\hline 16 & .78 & .63 & .61 & .88 & .32 & .77 \\
\hline
\end{tabular}

Note. $N=609$. All factor loadings and measurement error variances are significant $(p<.05)$. ML chi-square $(d f=20, p<.05)=341.67 ;$ GLS chi-square $(d f=20, p<.05)=233.00$. Composite reliability estimate $=.71$. 
Table B3

Employee Participation: Standardized Factor Loadings (SFL), Measurement Error Variances (MEV), And Item Reliability $\left(R^{2}\right)$

\begin{tabular}{ccccccc}
\hline & \multicolumn{3}{c}{ Maximum Likelihood } & \multicolumn{3}{c}{ Generalized Least Squares } \\
\cline { 2 - 7 } Item & SFL & MEV & $R^{2}$ & SFL & MEV & $R^{2}$ \\
\hline 17 & .72 & .84 & .52 & .77 & .64 & .60 \\
18 & .88 & .38 & .77 & .89 & .33 & .80 \\
19 & .88 & .37 & .77 & .89 & .32 & .79 \\
20 & .89 & .34 & .79 & .89 & .33 & .80 \\
21 & .86 & .48 & .74 & .88 & .42 & .77 \\
22 & .81 & .61 & .65 & .84 & .50 & .70 \\
\hline
\end{tabular}

Note. $N=609$. All factor loadings and measurement error variances are significant $(p<.05)$. ML chi-square $(d f=9, p<.05)=126.48$; GLS chi-square (df $=9, p<.05)=110.29$. Composite reliability estimate $=.69$.

Table B4

Peer Support: Standardized Factor Loadings (SFL), Measurement Error Variances (MEV), And Item Reliability $\left(R^{2}\right)$

\begin{tabular}{ccccccc}
\hline & \multicolumn{3}{c}{ Maximum Likelihood } & \multicolumn{3}{c}{ Generalized Least Squares } \\
\cline { 2 - 7 } Item & SFL & MEV & $R^{2}$ & SFL & MEV & $R^{2}$ \\
\hline 23 & .82 & .35 & .67 & .84 & .29 & .71 \\
24 & .86 & .32 & .74 & .89 & .25 & .78 \\
25 & .87 & .28 & .75 & .89 & .22 & .80 \\
26 & .84 & .43 & .70 & .86 & .36 & .74 \\
27 & .86 & .41 & .73 & .89 & .30 & .79 \\
28 & .81 & .49 & .65 & .85 & .35 & .73 \\
\hline
\end{tabular}

Note. $N=609$. All factor loadings and measurement error variances are significant $(p<.05)$. ML chi-square $(d f=9, p<.05)=233.89$; GLS chi-square ( $d f$ $=9, p<.05)=154.29$. Composite reliability estimate $=.75$. 
Table B5

Organizational Communication: Standardized Factor Loadings (SFL), Measurement Error Variances (MEV), And Item Reliability $\left(R^{2}\right)$

\begin{tabular}{ccccccc}
\hline & \multicolumn{3}{c}{ Maximum Likelihood } & \multicolumn{3}{c}{ Generalized Least Squares } \\
\cline { 2 - 7 } Item & SFL & MEV & $R^{2}$ & SFL & MEV & $R^{2}$ \\
\hline 29 & .75 & .71 & .56 & .80 & .51 & .65 \\
30 & .66 & .85 & .44 & .72 & .65 & .51 \\
31 & .93 & .21 & .87 & .94 & .18 & .89 \\
32 & .92 & .24 & .85 & .93 & .21 & .87 \\
33 & .85 & .52 & .71 & .88 & .39 & .77 \\
34 & .67 & 1.01 & .44 & .72 & .79 & .51 \\
\hline
\end{tabular}

Note. $N=609$. All factor loadings and measurement error variances are significant $(p<.05)$. ML chi-square $(d f=9, p<.05)=219.02$; GLS chi-square (df $=9, p<.05)=155.88$. Composite reliability estimate $=.65$.

Table B6

Work-life Balance: Standardized Factor Loadings (SFL), Measurement Error Variances (MEV), And Item Reliability $\left(R^{2}\right)$

\begin{tabular}{ccccccc}
\hline & \multicolumn{3}{c}{ Maximum Likelihood } & \multicolumn{3}{c}{ Generalized Least Squares } \\
\cline { 2 - 7 } Item & SFL & MEV & $R^{2}$ & SFL & MEV & $R^{2}$ \\
\hline 35 & .54 & 1.36 & .29 & .58 & 1.02 & .34 \\
36 & .67 & .92 & .45 & .70 & .74 & .48 \\
37 & .55 & 1.25 & .30 & .53 & 1.22 & .29 \\
38 & .78 & .65 & .60 & .84 & .46 & .70 \\
39 & .81 & .50 & .66 & .90 & .26 & .81 \\
40 & .82 & .51 & .67 & .83 & .44 & .69 \\
\hline
\end{tabular}

Note. $N=609$. All factor loadings and measurement error variances are significant $(p<.05)$. ML chi-square $(d f=9, p<.05)=270.57$; GLS chi-square ( $d f$ $=9, p<.05)=145.82$. Composite reliability estimate $=.58$. 
Table B7

Representation of Differences: Standardized Factor Loadings (SFL), Measurement Error Variances (MEV), And Item Reliability $\left(R^{2}\right)$

\begin{tabular}{ccccccc}
\hline & \multicolumn{3}{c}{ Maximum Likelihood } & \multicolumn{3}{c}{ Generalized Least Squares } \\
\cline { 2 - 7 } Item & SFL & MEV & $R^{2}$ & SFL & MEV & $R^{2}$ \\
\hline 41 & .44 & 1.28 & .19 & .48 & 1.08 & .23 \\
42 & .55 & 1.21 & .30 & .60 & .98 & .35 \\
43 & .61 & .98 & .37 & .72 & .62 & .52 \\
44 & .68 & .86 & .47 & .77 & .57 & .60 \\
45 & .86 & .42 & .74 & .89 & .33 & .79 \\
46 & .85 & .44 & .72 & .85 & .44 & .72 \\
\hline
\end{tabular}

Note. $N=609$. All factor loadings and measurement error variances are significant $(p<.05)$. ML chi-square $(d f=9, p<.05)=225.02 ;$ GLS chi-square ( $d f$ $=9, p<.05)=165.35$. Composite reliability estimate $=.48$.

Table B8

Affective organizational commitment: Standardized Factor Loadings (SFL), Measurement Error Variances (MEV), and Item Reliability $\left(R^{2}\right)$

\begin{tabular}{ccccccc}
\hline & \multicolumn{3}{c}{ Maximum Likelihood } & \multicolumn{3}{c}{ Generalized Least Squares } \\
\cline { 2 - 6 } Item & SFL & MEV & $R^{2}$ & SFL & MEV & $R^{2}$ \\
\hline 47 & .75 & .72 & .57 & .79 & .60 & .62 \\
48 & .65 & .97 & .42 & .66 & .93 & .43 \\
49 & .88 & .37 & .77 & .90 & .30 & .81 \\
50 & .89 & .33 & .80 & .90 & .31 & .81 \\
51 & .88 & .40 & .77 & .89 & .36 & .78 \\
52 & .89 & .33 & .79 & .90 & .30 & .81 \\
\hline
\end{tabular}

Note. $N=609$. All factor loadings and measurement error variances are significant $(p<.05)$. ML chi-square $(d f=9, p<.05)=92.17$; GLS chi-square ( $d f=$ $9, p<.05)=90.06$. Composite reliability estimate $=.68$. 
Table B9

Organizational Satisfaction: Standardized Factor Loadings (SFL), Measurement Error Variances (MEV), And Item Reliability $\left(R^{2}\right)$

\begin{tabular}{ccccccc}
\hline & \multicolumn{3}{c}{ Maximum Likelihood } & \multicolumn{3}{c}{ Generalized Least Squares } \\
\cline { 2 - 7 } Item & SFL & MEV & $R^{2}$ & SFL & MEV & $R^{2}$ \\
\hline 53 & .84 & .42 & .71 & .84 & .42 & .71 \\
54 & .94 & .12 & .89 & .94 & .13 & .90 \\
55 & .91 & .23 & .83 & .91 & .23 & .83 \\
56 & .83 & .32 & .68 & .83 & .42 & .68 \\
\hline
\end{tabular}

Note. $N=609$. All factor loadings and measurement error variances are significant $(p<.05)$. ML chi-square $(d f=2, p>.05)=0.68$; $\mathrm{GLS}$ chi-square $(d f=$ $2, p<.05)=0.67$. Composite reliability estimate $=.78$.

Table B10

Workgroup Satisfaction: Standardized Factor Loadings (SFL), Measurement Error Variances (MEV), And Item Reliability $\left(R^{2}\right)$

\begin{tabular}{ccccccc}
\hline & \multicolumn{3}{c}{ Maximum Likelihood } & \multicolumn{3}{c}{ Generalized Least Squares } \\
\cline { 2 - 7 } Item & SFL & MEV & $R^{2}$ & SFL & MEV & $R^{2}$ \\
\hline 57 & .93 & .14 & .87 & .93 & .14 & .87 \\
58 & .95 & .10 & .90 & .95 & .10 & .90 \\
59 & .84 & .23 & .70 & .84 & .23 & .71 \\
60 & .90 & .21 & .80 & .90 & .21 & .80 \\
\hline
\end{tabular}

Note. $N=609$. All factor loadings and measurement error variances are significant $(p<.05)$. ML chi-square $(d f=2, p>.05)=2.14$; GLS chi-square ( $d f=$ $2, p>.05)=2.06$. Composite reliability estimate $=.85$.

Table B11

Turnover Intentions: Standardized Factor Loadings (SFL), Measurement Error Variances (MEV), And Item Reliability $\left(R^{2}\right)$

\begin{tabular}{ccccccc}
\hline & \multicolumn{3}{c}{ Maximum Likelihood } & \multicolumn{3}{c}{ Generalized Least Squares } \\
\cline { 2 - 7 } Item & SFL & MEV & $R^{2}$ & SFL & MEV & $R^{2}$ \\
\hline 61 & .96 & .17 & .91 & .96 & .17 & .91 \\
62 & .87 & .52 & .76 & .87 & .52 & .76 \\
63 & .91 & .35 & .83 & .91 & .35 & .83 \\
\hline
\end{tabular}

Note. $N=609$. All factor loadings and measurement error variances are significant $(p<.05)$. Chi-square test not available because of insufficient degrees of freedom. Composite reliability estimate $=.74$. 


\section{HUMAN SUBJECTS APPROVAL}

Use of human subjects in the current study was reviewed and approved by the College Human Subjects Committee for exemption from IRB review on October 24, 2001. 


\title{
VITA
}

Bryan Christopher Hayes

3725 B Street. Lincoln, Nebraska 68510

\author{
EDUCATION \\ Old Dominion University \\ Norfolk, Virginia \\ Master of Science, Psychology, August 1996 \\ Bachelor of Science, Psychology, December 1993
}

University of Kansas

Lawrence, Kansas

Bachelor of Science, Business Administration \& Accounting, August 1985

PUBLICATIONS \& PRESENTATIONS

Hayes, B. C., Bartle, S. A., \& Major, D. A. (2002). Climate for Opportunity:

A Conceptual Model. Human Resource Management Review, 12, 1-24.

Bartle, S., Fink, A., \& Hayes, B. (2000). Psychology of the scientist. Attitudes regarding authorship issues in psychological publications.

Psychological Reports, 86, 71-788.

Bartle, S. \& Hayes, B. (1999). Organizational justice and work outcomes:

A meta-analysis. Poster presented at the $14^{\text {th }}$ Annual Conference for the Society for Industrial and Organizational Psychology. Atlanta, Georgia.

Turner, J. E., Hayes, B. C., Bartle, S., \& Green, A. P. (1999). OCBs, organizational spontaneity, prosocial behavior, contextual performance: Cleaning up the conceptual morass. Poster presented at the $14^{\text {th }}$ Annual Conference for the Society for Industrial and Organizational Psychology. Atlanta, Georgia.

Loviscky, G. E., Hayes, B. C., \& Fink, A. A. (1997). Results of the Student Network survey: Students' backgrounds, graduate program choices, career aspirations, and the graduate school experience. The industrialOrganizational Psychologist, 34(4), 120-125.

Hayes, B. C., Bartle, S. A., \& Major, D. A. (1997). Equal opportunity climate: A conceptual model. Paper presented at the fifty-seventh annual meeting of the Academy of Management, Boston, Massachusetts.

Hayes, B. C., Turner, J. E., \& Major, D. A. (1997). Prosocial behavior: Determinants of helping and cost of seeking help. Poster presented at the Twelfth Annual Conference of the Society for Industrial and Organizational Psychology, St. Louis, Missouri.

Hayes, B. C., \& Major, D. A. (April, 1995). Understanding more about outcomes. Paper presentation at the 87th Annual Meeting of the Southern Society for Philosophy and Psychology, Virginia Beach, Virginia.

Hayes, B. C. (1994). Teamwork at NASA Langley Research Center. Langley Aerospace Technical Report, LARSS, 1. 